\title{
Assembling Ni-Fe Layered Double Hydroxide 2D thin films for oxygen evolution electrodes
}

Rosa, Massimo; Bassetto, Victor Costa ; Girault, Hubert H.; Lesch, Andreas; Esposito, Vincenzo

Published in:

Applied Energy Materials

Link to article, DOI:

10.1021/acsaem.9b02055

Publication date:

2020

Document Version

Peer reviewed version

Link back to DTU Orbit

Citation (APA):

Rosa, M., Bassetto, V. C., Girault, H. H., Lesch, A., \& Esposito, V. (2020). Assembling Ni-Fe Layered Double Hydroxide 2D thin films for oxygen evolution electrodes. Applied Energy Materials, 3(1), 1017-1026.

https://doi.org/10.1021/acsaem.9b02055

\section{General rights}

Copyright and moral rights for the publications made accessible in the public portal are retained by the authors and/or other copyright owners and it is a condition of accessing publications that users recognise and abide by the legal requirements associated with these rights.

- Users may download and print one copy of any publication from the public portal for the purpose of private study or research.

- You may not further distribute the material or use it for any profit-making activity or commercial gain

- You may freely distribute the URL identifying the publication in the public portal 


\section{Article}

Subscriber access provided by DTU Library

\section{Assembling Ni-Fe Layered Double Hydroxide 2D thin films for oxygen evolution electrodes}

Massimo Rosa, Victor Costa Bassetto, Hubert H. Girault, Andreas Lesch, and Vincenzo Esposito

ACS Appl. Energy Mater., Just Accepted Manuscript • DOI: 10.1021/acsaem.9b02055 • Publication Date (Web): 03 Dec 2019

Downloaded from pubs.acs.org on December 3, 2019

\section{Just Accepted}

"Just Accepted" manuscripts have been peer-reviewed and accepted for publication. They are posted online prior to technical editing, formatting for publication and author proofing. The American Chemical Society provides "Just Accepted" as a service to the research community to expedite the dissemination of scientific material as soon as possible after acceptance. "Just Accepted" manuscripts appear in full in PDF format accompanied by an HTML abstract. "Just Accepted" manuscripts have been fully peer reviewed, but should not be considered the official version of record. They are citable by the Digital Object Identifier (DOI®). "Just Accepted" is an optional service offered to authors. Therefore, the "Just Accepted" Web site may not include all articles that will be published in the journal. After a manuscript is technically edited and formatted, it will be removed from the "Just Accepted" Web site and published as an ASAP article. Note that technical editing may introduce minor changes to the manuscript text and/or graphics which could affect content, and all legal disclaimers and ethical guidelines that apply to the journal pertain. ACS cannot be held responsible for errors or consequences arising from the use of information contained in these "Just Accepted" manuscripts. 


\title{
Assembling Ni-Fe Layered Double Hydroxide 2D thin films for oxygen evolution electrodes
}

\author{
Massimo Rosa, ${ }^{1, *}$ Victor Costa Bassetto, ${ }^{2}$ Hubert H.Girault, ${ }^{2}$ Andreas Lesch, ${ }^{3,}$ * Vincenzo Esposito ${ }^{1, *}$ \\ ${ }^{1}$ DTU Energy, Technical University of Denmark, Risø Campus, Frederiksborgvej 399, 4000, Roskilde, \\ Denmark \\ ${ }^{2}$ Laboratory of Physical and Analytical Electrochemistry, École Polytechnique Fédérale de Lausanne \\ (EPFL) Valais Wallis, Rue de l'Industrie 17, 1950 Sion, Switzerland. \\ ${ }^{3}$ Department of Industrial Chemistry "Toso Montanari", University of Bologna, Viale del Risorgimento \\ 4, 40136 Bologna, Italy.
}

${ }^{*}$ CORRESPONDING AUTHORS FOOTNOTE

EMAILS: andreas.lesch@unibo.it, vies@dtu.dk,massimo.rosa@ymail.com 


\begin{abstract}
:
Continuous hydrothermal flow synthesis (CHFS) of Ni-Fe Layered Double Hydroxide (LDH) leads to waterborne dispersions of $2 \mathrm{D}$ nanoplatelets in the range of $10-50 \mathrm{~nm}$ in lateral size. Conversion of the as-synthesized LDH nanoplatelet dispersion into inkjet printing inks results in high precision patterning and complete substrate coverage with low LDH loadings in the range of $\mu \mathrm{g} \cdot \mathrm{cm}^{-2}$. The Ni-Fe LDHs' anisotropy induces a preferential in-plane alignment to a glassy carbon substrate producing low porosity films. Thin Ni-Fe LDH films in the submicrometer range exhibit superior electrocatalytic activity for the oxygen evolution reaction (OER), with an overpotential of $270 \mathrm{mV}$ at $10 \mathrm{~mA} \cdot \mathrm{cm}^{-2}$ and a Tafel slope of $32 \mathrm{mV} \cdot \mathrm{dec}^{-1}$. The particle alignment creates a compact film and induces a loading-independent electrochemical performance of the Ni-Fe LDH electrodes for loadings above $50 \mu \mathrm{g} \cdot \mathrm{cm}^{-2}$. The combination of CHFS and inkjet printing represents a promising hyphenation of large-scale synthesis and electrode production.
\end{abstract}

Keywords: 2D materials, nanostructures, layered double hydroxide, oxygen evolution reaction, continuous hydrothermal synthesis, inkjet printing. 


\section{Introduction}

Nanostructured materials show unique properties with the potential for improving the performances of key energy conversion devices such as batteries, fuel cells, and electrolyzers ${ }^{1}$. Among all the investigated nanostructures, 2D nanomaterials attracted considerable interest due to their outstanding properties ${ }^{2}$. Compared to nanoparticles and nanowires, $2 \mathrm{D}$ materials expose a single lattice plane, so that a large part of their chemical properties depends directly on specific crystallographic orientations. This unique feature for controlling the material surface chemistry exhibits high potential for applications in catalysis and electrocatalysis ${ }^{3}$.

In this context, layered double hydroxides ( $\mathrm{LDH})$ form one of the most studied groups of 2D catalysts for energy applications ${ }^{4}$. This phase consists of 2D brucite-like layers with stoichiometry $\left[\mathrm{M}^{\mathrm{II}}{ }_{1-x} \mathrm{M}^{\mathrm{III}}{ }_{x}(\mathrm{OH})_{2}\right]^{x+}$ intercalated by anions for compensating the positive charge excess ${ }^{5,6}$. Ni-Febased LDHs show high catalytic activity towards the oxygen evolution reaction (OER) with remarkable stability ${ }^{7-9}$. In addition, exfoliation, compositional tuning, and exchange of the intercalating anion make them a versatile material suitable for integration into various nanostructures and composites ${ }^{10}$. Therefore, Ni-Fe LDHs represent promising candidates for replacing precious metals ${ }^{11}$ as active materials for water oxidation in energy applications ${ }^{12}$. Recently, also the combination of Ni-Fe LDH with other materials has been reported to enhance the OER activity avoiding the use of expensive and scarce elements. A few examples from literature are: $\mathrm{Ni}-\mathrm{Fe} \mathrm{LDH}$ deposited on $\mathrm{Co}, \mathrm{N}$-codoped carbon nanoframes ${ }^{13}$, $\mathrm{Ni}-\mathrm{Fe} \mathrm{LDH}$ deposited on $\mathrm{Au}{ }^{14}$, the introduction of cation vacancies ${ }^{15}$ and synthesizing $\mathrm{NiO} / \mathrm{Ni}-\mathrm{Fe} \mathrm{LDH}$ composites ${ }^{9}$ or hierarchical hollow (Co,Ni)Se ${ }_{2} @ \mathrm{Ni}-\mathrm{Fe}$ LDH nanocages ${ }^{16}$.

However, various issues still limit the exploitation of these and other nanomaterials for energy applications on a large scale. These limitations span from health and environmental issues ${ }^{17}$ to 
agglomeration ${ }^{18}$ and heterogeneous composition and morphology of the products ${ }^{19}$. This last lack of uniformity mainly stems from the batch processes employed in nanomaterial synthesis. Hence, unleashing the application of nanomaterials requires novel synthetic and processing approaches that allow reducing the impact of nanomaterials' production and increase product quality.

Continuous hydrothermal flow synthesis (CHFS) is emerging as an easily scalable technology for producing water dispersions of metal, metal oxide, and metal hydroxide nanoparticles ${ }^{20}$. Compared to batch processes, CHFS ensures uniform reaction conditions. This method provides constant supersaturation conditions at the mixing stage, reducing the heterogeneity of produced nanomaterials. LDH 2D-nanoplatelets have been synthesized by CHFS, using a broad array of cations at both the divalent and trivalent sites ${ }^{21-24}$. In Ni-Fe LDH, typical preparation approaches consist of hydro- or solvo-thermal batch processes with long synthesis times ${ }^{25-27}$, but Ni-Fe LDH can also be prepared by electrochemical deposition ${ }^{28}$. These synthetic routes support the heterogeneity mentioned above: in such slow processes the composition of the reaction environment evolves with time so that particles nucleated and grown at different stages experience a different chemical environment. The application of CHFS to the synthesis of Ni-Fe LDH would increase the control over the particles' composition and morphology.

CHFS products represent an attractive starting point for liquid processing of nanomaterials by inkjet printing ${ }^{29,30}$. The combination of these two technologies indeed prevents the handling of dried nanopowders, reducing the environmental impact, and agglomeration risks. In some cases, using nanodispersions produced by CHFS allowed the formulation of inks without organic binders or dispersants ${ }^{29,30}$, which influence the surface properties of the deposited material. In addition, converting the CHFS products into inks makes it possible to control the deposition of picolitersized droplets with a spatial resolution of a few tens of microns. Due to its miniaturization and 
customization capabilities, the inkjet technology can be used for printing patterns and films of an extensive range of nanomaterials ${ }^{31,32}$.

Inkjet printing is particularly interesting in the case of $2 \mathrm{D}$ nanomaterials, where the particles' anisotropy govern the alignment of the printed particles ${ }^{33} .2 \mathrm{D}$ particles preferentially orient parallel to the substrate, enhancing inter-particle and substrate-particle interactions. The alignment may lead to a size-dependent coffee ring effect ${ }^{34}$, but also enhances the substrate adhesion and enables the fabrication of heterostructures ${ }^{35-40}$.

In this work, we explore the combination of CHFS and inkjet printing as a scalable strategy for the synthesis and assembling of 2D nanomaterials in thin film electrodes, taking advantage of the NiFe LDH 2D morphology. In particular, the synthesis of Ni-Fe LDH by CHFS produced nanoplatelet dispersions that required a colloidal and rheological optimization to comply with the strict agglomeration, viscosity, and surface tension requirements for inkjet printing. The printing process employed the formulated inks to deposit thin Ni-Fe LDH films with precise particle orientation onto glassy carbon substrates. To the best of our knowledge, this is the first reported work on inkjet printing of pure LDH inks. The performance of the Ni-Fe LDH electrodes was analyzed for the OER.

\section{Experimental}

Materials and chemicals

$\mathrm{Ni}\left(\mathrm{NO}_{3}\right)_{2} \cdot 6 \mathrm{H}_{2} \mathrm{O}, \mathrm{Fe}\left(\mathrm{NO}_{3}\right)_{3} \cdot 9 \mathrm{H}_{2} \mathrm{O}, \mathrm{KOH}, \mathrm{K}_{2} \mathrm{CO}_{3}$, (all purchased from Sigma Aldrich) were used for the hydrothermal synthesis of Ni-Fe LDH. 1,2-propylene glycol (1,2-PG, Sigma Aldrich) and isopropanol (iPA, Sigma Aldrich) were employed for the preparation of the LDH inks. All compounds were of analytical grade and used as-received. An ink containing $\mathrm{Ir} / \mathrm{C}$ as a reference 
material was formulated starting from Ir nanoparticles supported on carbon black ( $\mathrm{Ir} / \mathrm{C}, 40 \mathrm{wt} \%$, Fuel Cell Store).

A UV curable dielectric ink from SunChemical (EMD 6415 dielectric ink) was used as an insulating material to define precisely the active area of the electrodes for electrochemical characterization and material comparisons.

\section{Synthesis of Ni-Fe LDH and material characterization}

Continuous hydrothermal flow synthesis of Ni-Fe LDHs was carried out using a CHFS reactor, which was described elsewhere in detail ${ }^{41}$. Briefly, a stream of water at $170{ }^{\circ} \mathrm{C}$ was mixed at a flow rate of $20 \mathrm{~mL} \cdot \mathrm{min}^{-1}$ in a first mixing stage with an alkaline stream consisting of $\mathrm{KOH} 1$ $\mathrm{mol} \cdot \mathrm{L}^{-1}$ at room temperature and $\mathrm{K}_{2} \mathrm{CO}_{3} 0.2 \mathrm{~mol} \cdot \mathrm{L}^{-1}$ at $10 \mathrm{~mL} \cdot \mathrm{min}^{-1}$. The resulting flow was mixed in a second mixing stage with a stream of precursors containing $0.075 \mathrm{~mol} \cdot \mathrm{L}^{-1}$ of $\mathrm{Ni}\left(\mathrm{NO}_{3}\right)_{2}$ and $0.025 \mathrm{~mol} \cdot \mathrm{L}^{-1} \mathrm{Fe}\left(\mathrm{NO}_{3}\right)_{3}$. The temperature after mixing was $80{ }^{\circ} \mathrm{C}$. The mixed stream passed through a re-heater that was set at $80{ }^{\circ} \mathrm{C}$, resulting in a residence time of the reactants at this temperature of $37 \mathrm{~s}$. The pressure inside the reactor was controlled downstream and set at 200 bar, which is required for process flow stability in our setup. The products were eventually depressurized and cooled down at room temperature for collection. The obtained products were purified by centrifuging and re-dispersing the particles in clean DI water several times ${ }^{42}$.

The obtained dispersion, referred to in the next sections as CHFS dispersion, had a $\mathrm{pH}$ of 9 and was used as the starting point for the formulation of the inkjet printable ink (LDH ink) (vide infra). After solvent evaporation, the dried powder from the dispersion was characterized by X-ray diffraction employing a Bruker D8 ( $\mathrm{Cu} \mathrm{K} \alpha$ radiation) measuring with a $0.025^{\circ} / 2 \mathrm{~s}$ step size / step time. The particle morphology and composition were analyzed using a Jeol 3000F TEM microscope equipped with an Oxford Instrument EDX detector. 


\section{Inkjet ink formulation and characterization}

The Ni-Fe LDH ink was formulated by mixing the aqueous CHFS dispersion with a) 1,2-PG to increase the viscosity $(\eta)$ and to lower the evaporation rate and with b) iPA to decrease the surface tension $(\sigma)$. The resulting mixture was processed in a Sonics Vibra Cell 505 in a "cup horn" configuration alternating $5 \mathrm{~s}$ bursts at $30 \%$ amplitude and $5 \mathrm{~s}$ of rest for a total processing time of $30 \mathrm{~min}$. The ink had a final Ni-Fe LDH solid loading of $1.4 \%$ wt. The viscosity was measured with an Anton Paar MCR 302 rheometer in rotational mode (50 mm diameter cone-plate configuration), increasing the shear rate from 1 to $1000 \mathrm{~s}^{-1}$. The surface tension was measured using a drop shape analyzer DSA-30 (Krüss). The dimensionless printability parameter $Z$ was used to predict the ink characteristics for printing and was defined as the inverse of the Ohnesorge number: $Z=\left(\sigma^{*} \rho *\right.$ $a)^{1 / 2} / \eta^{43}$, where $a$ is the nozzle diameter and $\rho$ the density of the ink. For calculating $Z$, the value of viscosity at $1000 \mathrm{~s}^{-1}$ was considered. Solvent ratios were adjusted to reach $1<Z<10$ and achieve thus optimal printing performance as suggested by Derby ${ }^{43}$.

The colloidal stability of the Ni-Fe LDH inks and CHFS dispersions was analysed by using static multiple light scattering with a Turbiscan LAB (Formulaction). The dispersions and inks were monitored by scanning with a laser vertically, i.e., from top to bottom, a sample containing vial. Every $40 \mu \mathrm{m}$, the laser intensity transmitted and backscattered by the sample were recorded, constructing an intensity profile along the sample height. Samples were scanned for 5 days with a scanning frequency of $30 \mathrm{~s}$. The variation of these signals over time was a measure of dispersion stability by detecting vertical variations of the particle concentration in the CHFS dispersions and LDH inks.

The Ir/C ink was formulated by first adding Ir/C powder to a water:iPA (1:1) mixture, which was then sonicated for $15 \mathrm{~min}$ at 30\% amplitude with on/off cycles of $5 \mathrm{~s}$ using the Sonics Vibra Cell 
505 in the "cup horn" arrangement. The $\mathrm{Ir} / \mathrm{C}$ inkjet ink contained $3 \mathrm{mg} \cdot \mathrm{mL}^{-1}$ of $\mathrm{Ir} / \mathrm{C}$ and 0.6 $\mathrm{mg} \cdot \mathrm{mL}^{-1}$ of Nafion and was stirred in a vortex agitator for full homogenization.

\section{Inkjet printing}

A Fujifilm Dimatix DMP-2850 drop-on-demand (DOD), piezoelectric inkjet printer was used for depositing the Ni-Fe LDH and Ir/C inks. The catalysts were printed onto polished glassy carbon (GC, Sigradur K, HTW) rods and plates as conductive supports for rotating disc and static electrochemical measurements, respectively. An X-Serie Ceraprinter from Ceradrop was employed for masking the plate samples with the UV curable dielectric ink, leaving a $3 \times 3 \mathrm{~mm}^{2}$ window on the electrode material for the electrochemical characterization. UV photopolymerization was achieved simultaneously to inkjet printing with a UV LED (FireEdge FE300 380-420nm, Phoseon Technology), which was installed next to the printhead. Both inkjet printers were equipped with disposable, piezoelectric-based cartridges (DMC-11610, Dimatix) containing 16 individually addressable nozzles with an orifice of $\sim 21 \mu \mathrm{m}$ in diameter.

$\mathrm{Ni}-\mathrm{Fe}$ LDH inks were jetted using an optimized sigmoidal waveform and jetting frequency for the piezoelectric actuation inside the nozzles of the cartridges. The droplet spacing was optimized, resulting in a value of $35 \mu \mathrm{m}$ at a printing bed temperature of $42{ }^{\circ} \mathrm{C}$. These conditions were used for all fabrications reported herein. Two different material loadings, i.e., $50 \mu \mathrm{g} \cdot \mathrm{cm}^{-2}$ and 150 $\mu \mathrm{g} \cdot \mathrm{cm}^{-2}$, were prepared on the GC plates for analysing the OER activity. GC rods were loaded with $60 \mu \mathrm{g} \cdot \mathrm{cm}^{-2}$ for the chronopotentiometric analysis. The loadings were calculated based on the accurately known concentration of the material in the ink, droplet volume, and the number of deposited droplets per substrate area. The droplet volume was calculated by the analysis of the camera recordings during the jetting tests using Image ${ }^{44}$. The same approach was used for measuring the splat diameter of the as-printed droplets on the GC substrate. The average and 
standard deviation of the droplet size on the substrate were estimated by measuring the diameter of 60 splats.

The microstructure of the printed Ni-Fe LDH films was characterized via SEM using a Zeiss Merlin microscope. The final thickness of the films was measured with the same instrument from the sample cross section that was prepared by cutting the coated substrates with a diamond saw and polishing the cut side after embedding the substrate in epoxy resin.

Ir/C electrodes were inkjet-printed utilizing the DMP-2850 printer with optimized printing parameters (e.g., waveform and jetting frequency) on GC plates, which were kept at room temperature during printing. The number of printed layers and droplet spacing were calculated in order to achieve an Ir loading corresponding to the Ni-Fe LDH loading, generally $50 \mu \mathrm{g} \cdot \mathrm{cm}^{-2}$ and $150 \mu \mathrm{g} \cdot \mathrm{cm}^{-2}$.

\section{Electrochemical characterization}

The OER activity of the printed samples was measured using a custom-made electrochemical cell with a three-electrode configuration. A glassy carbon substrate coated with the Ni-Fe LDHs or Ir/C served as working electrode (WE), which was mounted on the bottom of the cell. A Pt mesh, or Pt coil, and a $\mathrm{Ag} / \mathrm{AgCl} / 1 \mathrm{M} \mathrm{KCl}$ electrode were used as counter electrode (CE) and reference electrode (RE), respectively. The rods, coated with the inkjet-printed films, were mounted on a rotating shaft for operating the system as a rotating disc electrode (RDE). All measurements were conducted in $0.1 \mathrm{M} \mathrm{KOH}$ and the potential of the RE was calibrated for each measurement with a reversible hydrogen electrode (RHE) HydroFlex (Gaskatel). All potentials herein are referred to the RHE. An Autolab PGSTAT204 potentiostat with a frequency response analyser module FRA32M (Metrohm) was used for all measurements. The uncompensated resistance was measured using electrochemical impedance spectroscopy (EIS) and used for $i R$-drop correction. 
The measuring protocol consisted of a single cycle cyclic voltammogram (CV) between 1.07 $1.67 \mathrm{~V}$ at a scan rate of $40 \mathrm{mV} \cdot \mathrm{s}^{-1}$, followed by recording a polarization curve at $5 \mathrm{mV} \cdot \mathrm{s}^{-1}$. The samples were then cycled for 50 times at $40 \mathrm{mV} \mathrm{s}^{-1}$. This step was followed by a $\mathrm{CV}$ at $40 \mathrm{mV} \cdot \mathrm{s}^{-1}$ and polarization curve at $5 \mathrm{mV} \cdot \mathrm{s}^{-1}$. The polarization curves before and after the aging/activating were compared.

\section{Results and discussion}

A waterborne dispersion of Ni-Fe LDH nanoplatelets was produced by a continuous hydrothermal flow synthesis (CHFS) process with a high volumetric production rate of $2.4 \mathrm{~L} \mathrm{~h}^{-1}$, corresponding to ca. $3.4 \mathrm{~g} \mathrm{~h}^{-1}$ of LDH (with the measured reaction yield of 57\%) The peculiar short residence time of this process was the key to synthesize nanosized Ni-Fe LDH platelets. From the BF-TEM images shown in Fig. 1a, it can be concluded that the residence time of $37 \mathrm{~s}$ limited the particle growth to nanoplatelets with lateral size $<50 \mathrm{~nm}$. This small platelet size was essential for the aim of producing LDH-coated electrodes by using inkjet printing (vide infra). The BF-TEM analysis indicated further the formation of strongly anisotropic 2D particles with a hexagonal crystalline habit (Fig. 1a). An additional BF-TEM micrograph is provided in the supplementary information (Fig. S1), giving a more complete picture of the particles' size and morphology. 

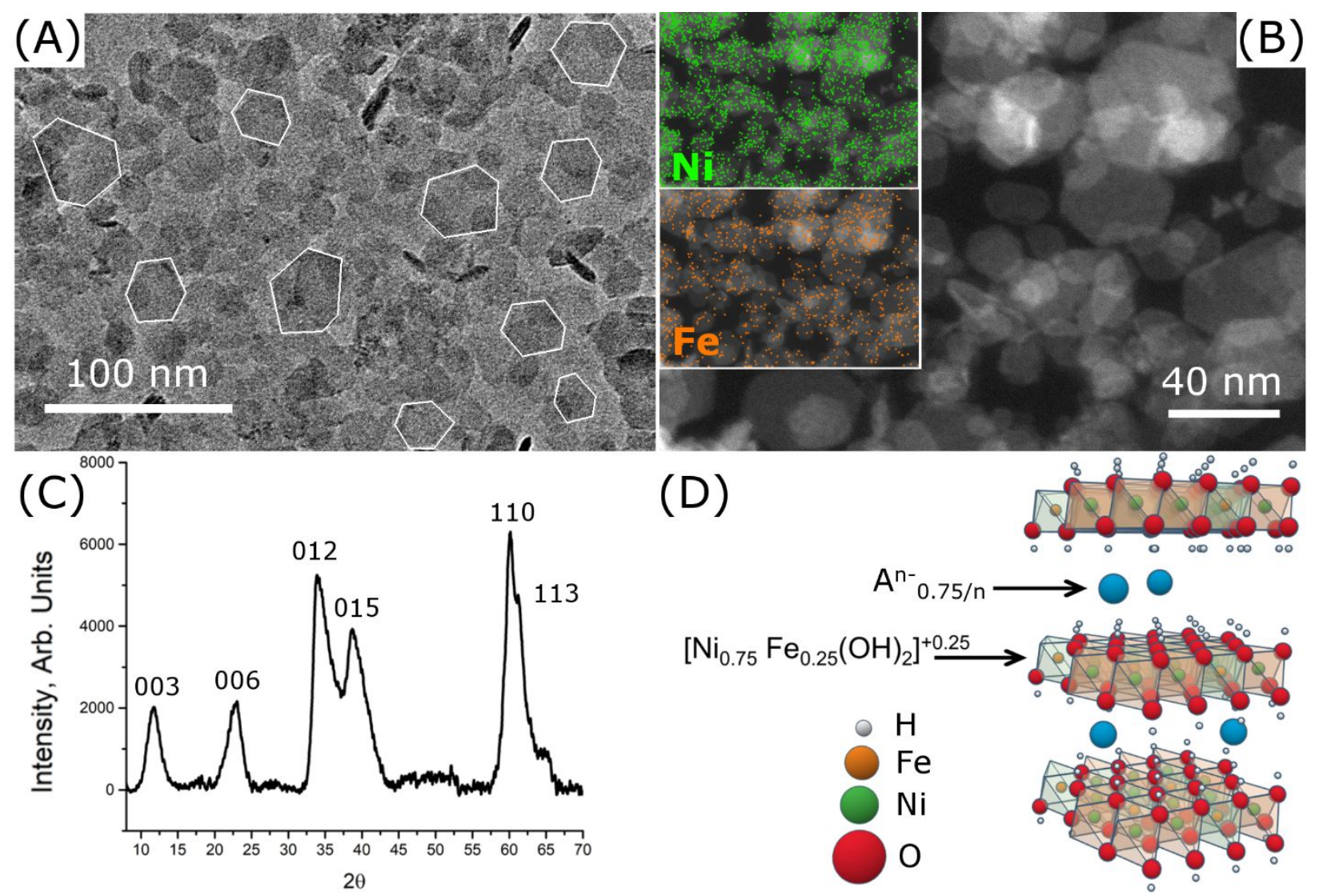

(D)
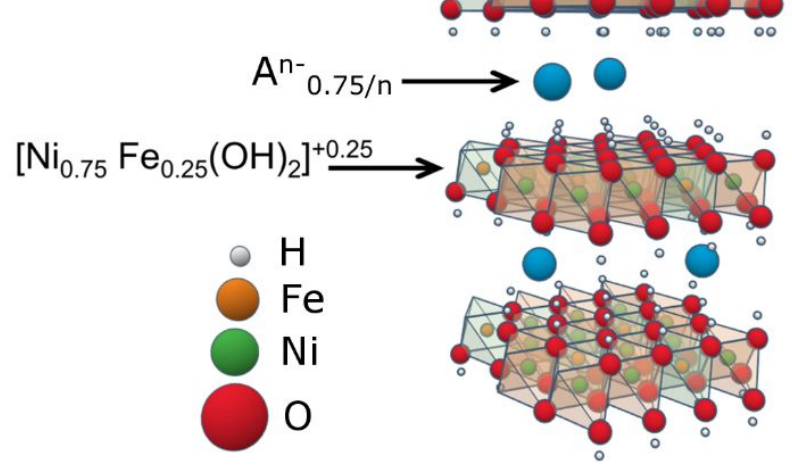

Figure 1. a) BF-TEM image of the as-produced Ni-Fe LDH nanoplatelets (white lines around 10 exemplary nanoplates were added as guides to the eye), b) STEM image with EDX mapping shows Ni and Fe distribution in the insets, c) powder XRD pattern and d) model of the structure based on the data collected. $A^{n-}$ represents the intercalating anions for compensating the positive charge of the hydroxide layers. Due to the precursor composition, $\mathrm{A}^{\mathrm{n}-}$ consists of $\mathrm{NO}_{3}{ }^{-}$and $\mathrm{CO}_{3}{ }^{2-}$.

STEM/EDX and XRD provide further chemical and structural information of the as-produced material. The elemental mapping in Fig. 1b reveals that the sample consisted of particles containing $\mathrm{Ni}$ and $\mathrm{Fe}$, which were both incorporated in the same structure. In addition, the quantification of the EDX data resulted in an elemental composition of 76:24 Ni:Fe at\%, which was very close to the stoichiometry of the metal precursor solution for the CHFS, i.e., 75:25. The XRD pattern in Fig. 1e confirmed the hydrotalcite-like structure exhibited by LDH materials with typical (003) and (006) basal peaks ${ }^{42,45}$. The combination of these results led to the univocal determination of the phase as Ni-Fe LDH (Fig. 1d). The different broadening of the diffractogram 
peaks provided additional structural information. Broadening was more pronounced in peaks with $1 \neq 0$, while (110) was the sharpest reflection. Therefore, the material showed an anisotropic disorder along the $\mathrm{c}$ direction resulting from the nanometric thickness and the stacking disorder of the hydroxide layers. Non-uniform stacking might result from the intercalation of different anions available in the reaction environment, i.e., $\mathrm{NO}_{3}{ }^{-}$and $\mathrm{CO}_{3}{ }^{2-}$, which induced different interlayer spacing. Additionally, the CHFS process was carried out in a kinetic regime with short residence times that could prevent the formation of highly ordered phases at a temperature as low as $80^{\circ} \mathrm{C}$. The presence of defects in the crystalline structure is also evidenced by the presence of a shoulder at the $2 \theta$ angle of ca. $65^{\circ}$, which is not associated to a perfectly ordered NiFe LDH structure.

Besides peak broadening, the XRD pattern showed (003) and (006) reflections with extremely low intensity compared to many examples in literature ${ }^{46-48}$. Literature reports an intensity reduction of these peaks after decreasing the particle thickness via exfoliation ${ }^{49,50}$. Therefore, we believe that thin platelets consisting of a few stacked layers were synthesized by CHFS, resulting in weaker diffraction from the basal planes. The low intensity of (003) and (006) observed herein along with the weak image contrast in the BF-TEM analysis (Fig 1(a) and S1), suggest the formation of extremely thin nanoplatelets with pronounced 2D morphology.

Obtaining an inkjet printable LDH ink required the conversion of the CHFS dispersion into a stable colloid with proper viscosity and surface tension. The as-produced aqueous CHFS dispersion exhibited a high surface tension of $71 \mathrm{mN} \cdot \mathrm{m}^{-1}$ and low viscosity of $1.9 \mathrm{mPa}$ s at $1000 \cdot \mathrm{s}^{-1}$ (see viscosity analysis in Fig. 2a). This combination resulted in a printability value of 20, mainly because the surface tension value exceeded the jetting capability of the used cartridge $\left(\sim 30 \mathrm{mN} \cdot \mathrm{m}^{-1}\right.$ is the ideal value). 
Fig. 2a also shows a non-Newtonian behaviour of the CHFS dispersion, which represents a limiting aspect for the jetting performance of a fluid. In order to achieve inkjet printability, iPA ( $\sigma$ $\left.=\sim 22 \mathrm{mN} \cdot \mathrm{m}^{-1}\right)$ and 1,2-PG $(\eta=\sim 40 \mathrm{mPa} \cdot \mathrm{s})$ were added to the CHFS dispersion to lower the surface tension and to increase the viscosity, respectively. The $\mathbf{L D H}$ ink formulation led to a $Z$ value of 5.1 and converted the shear thinning behaviour of the CHFS dispersion in a quasiNewtonian one (Fig. 2a). Ink stability was analysed to evaluate the degradation of the jetting performance with time. Storing the fresh $\mathbf{L D H}$ ink for three days decreased its $Z$ value from 5.1 to 3.3 (Fig. 2a), which then remained stable. A more pronounced shear thinning was detected and 
affected inkjet printing (vide infra), suggesting that the application of fresh ink, obtained by taking the CHFS dispersion directly from the reactor and mixing it with the ink solvents, is recommended. Sedimentation analysis of both the CHFS dispersion and LDH ink (kept without agitation) provided a more accurate description of the colloids' evolution in time. As first analysed by eye, the CHFS dispersion showed the precipitation of a sediment after 6 days, while no sedimentation occurred in the LDH ink (Fig. 2b). The sedimentation process was then quantitatively analysed by static light scattering measurements during $120 \mathrm{~h}$ (Fig. 2c and Fig. 2d). The CHFS dispersion exhibited the typical evolution of a precipitating colloid: at the top of the sample, the backscattering intensity decreased due to the reduction of the particle content (clarification). At the bottom, the intensity increased due to the settling of material (sedimentation). On the opposite, the LDH ink displayed an overall increase of the backscattered intensity, particularly marked near the bottom of the test vial. This effect resulted most likely from the formation of particle aggregates with diameters smaller than the incident laser wavelength, i.e., $880 \mathrm{~nm}{ }^{51}$. The aggregation explained the appearance of a shear thinning behaviour of the LDH ink, but its higher viscosity compared to the CHFS dispersion prevented sedimentation.

The as-prepared $\mathbf{L D H}$ ink with $Z=5.1$ showed an optimal jetting behaviour, i.e., stable spherical droplets with a straight falling direction (Fig. 3a). This result is particularly notable considering the simple, dispersant-free formulation of the LDH ink. Fig. 3a indicates the formation of spherical droplets from parallel nozzles with a droplet volume of $\sim 7 \mathrm{pL}$, jetted at 1 $\mathrm{kHz}$ jetting frequency. After 3 days of storing, jetting of the $\mathbf{L D H}$ ink became unstable despite a calculated $Z$ value of 3.1. This failure was most likely the result of nozzle clogging due to a combination of the presence of larger nanoplatelet aggregates and the appearance of non-ideal Newtonian behaviour (vide supra). Indeed, the size of the dispersed particulate that can be jetted 
is limited, as a rule of thumb, to $1 / 50^{\text {th }}$ of the nozzle diameter for optimal printing ${ }^{52}$. Therefore, in this work, aggregates larger than $400 \mathrm{~nm}$ could spoil or even hinder the printing process. In literature, only very few approaches to print LDH materials can be found, which is an indication of the practical issues that are faced to make a printable ink. So far, to the best of our knowledge, only Wei et al. reported a Co-Al LDH/silver nanowire hybrid ink for the production of bending sensors ${ }^{53}$.
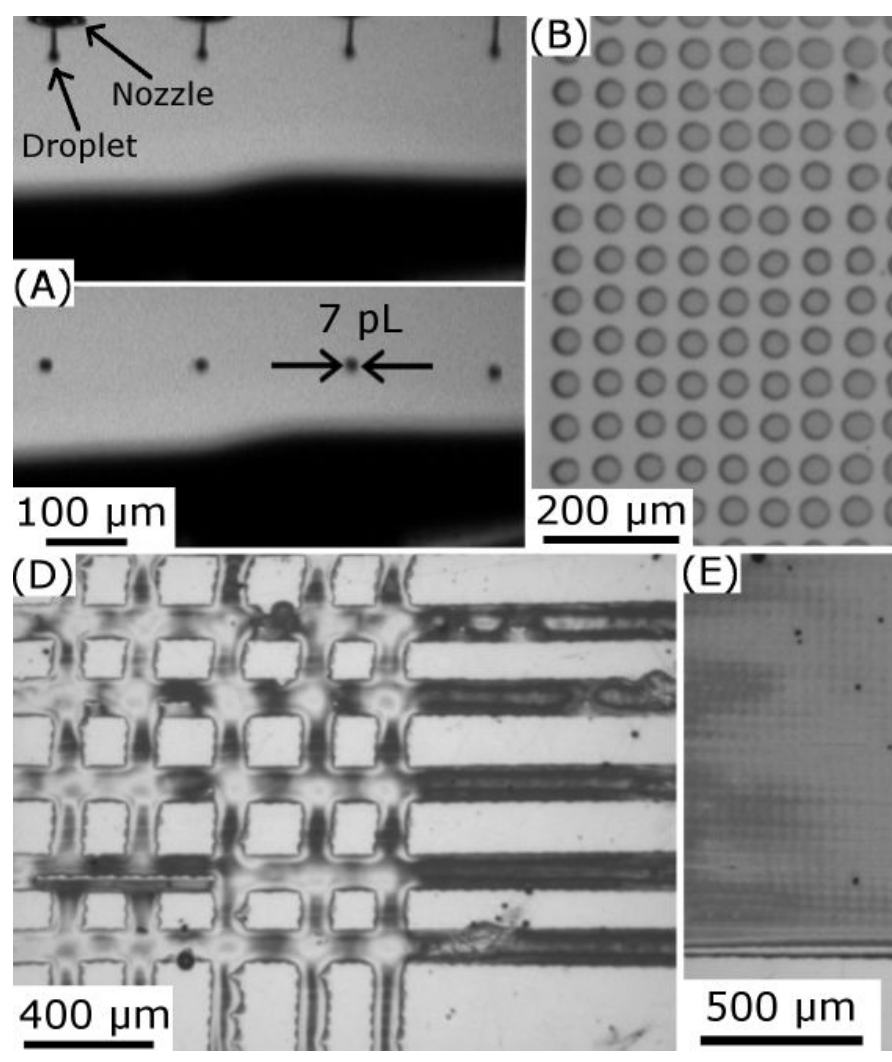

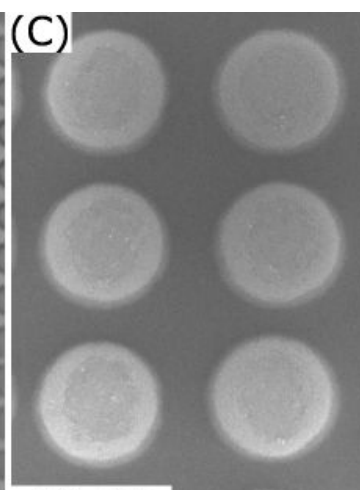

$50 \mu \mathrm{m}$

Printed NiFe LDH

Figure 3. Jetting and printing behaviour of the Ni-Fe LDH ink. a) Droplet ejection and formation from four exemplary adjacent nozzles (up: droplets being just expelled from the nozzles, thus, showing a tail; down: spherical, tail-free droplets during flight), b) printed droplet array onto glassy carbon, c) SEM image of separated splats (i.e., LDH ink droplets on the substrate) after solvent evaporation. d) An exemplary grid pattern of printed LDH ink onto glassy carbon, e) full coverage film printed onto glassy carbon with a particle loading of $70 \mu \mathrm{g} \cdot \mathrm{cm}^{-2}$. Note: the dark spots in (b) and (e) are features from the GC surface. In all cases, the printing direction was from left to right. 
The printing performance of the fresh LDH ink was investigated first by depositing droplet arrays and patterns onto a glassy carbon surface. Fig. 3b and Fig. 3c show the repeatable formation of single splats with a mean diameter of $(44 \pm 4) \mu \mathrm{m}(\mathrm{N}=60)$, representing the size of the smallest printable feature for this process using the DMP inkjet printer. As highlighted by these images, a remarkable accuracy of the droplet placing was achieved in $x$ - and $y$-directions. SEM analysis of the splats after solvent evaporation indicated a rather homogeneous solid deposit with a minor coffee ring, i.e., a slightly larger abundance of material is observed at the rim of the splats (Fig. 3c). The accuracy and high resolution of the printing process allowed the deposition of welldefined micro-sized patterns (Fig. 3d, track width $100 \mu \mathrm{m}$ ) as well as defect-free, homogeneous films (Fig. 3e). In particular, the construction of the grid pattern in Fig. 3d demonstrates the advantage of using inkjet printing. Indeed, LDH materials are currently considered as candidates for charge storing materials in supercapacitors with micropatterned electrodes ${ }^{54-56 .}$ Micropatterned LDH films found recently also interesting applications in microresistor fabrication ${ }^{57}$ and drug testing on live cell cultures ${ }^{58}$. Screening libraries of micro-sized spots of various LDH compositions is attractive when a large amount of materials and parameters need to be investigated in parallel ${ }^{59}$. Furthermore, it is recently discussed in literature that micropatterned catalyst layers could affect the wetting of the electrodes facilitating the detachment of generated gas bubbles that can temporarily block the active electrode surface area ${ }^{60}$. Micropatterned OER electrocatalyst films could further be of interest in miniaturized and portable devices ${ }^{61}$. The present approach could, therefore, be relevant not only in the field of energy research. 
The optimized inkjet printing process was then employed for the deposition of continuous

Figure 4. a) Exemplary printed electrode for electrochemical analysis with inkjet-printed Ni-Fe LDH pattern (dashed line), masking area (red shadowed area with solid lines) and working electrode area (greenish appearing square in the centre). b) SEM image of the microstructure of the as-printed $\mathrm{Ni}$-Fe LDH nanoplatelets. Cross-sections of the printed Ni-Fe LDH films on glassy carbon plates with $50 \mu \mathrm{g} \cdot \mathrm{cm}^{-2}$ loading (c) and $150 \mu \mathrm{g} \cdot \mathrm{cm}^{-2}(\mathrm{~d})$.

films over square millimeter-sized areas as electrode coating for electrochemical applications and analysis. Fig. 4a shows the typical test electrode configuration for static electrochemical measurements (unstirred solution) after all printing steps (further details in Supporting Information SI-2). The square with the dashed line highlights the area of the printed Ni-Fe LDH film ("printed film"). The reddish frame emphasizes the polymeric insulating "mask" printed to define a $3 \times 3 \mathrm{~mm}^{2}$ window of the $\mathrm{LDH} / \mathrm{GC}$ electrode ("exposed material for testing"). Please note 
that the colour appearances are the result of optical effects caused by light reflection and substrate angle. The small patterns on the left of the substrate originate from printing tests usually performed before each new printing process to control and possibly slightly adjust the printing parameters ("printing tests"). These patterns were insulated by the polymeric mask and therefore inactive during all electrode characterizations.

Inkjet printing and solvent drying resulted in a preferential orientation of the Ni-Fe LDH nanoplatelets onto the GC surface, as it can be seen in the SEM micrograph in Fig. 4b. The LDH nanoplatelets covered the substrate mostly by a exposing the crystallographic basal plane of the nanoplatelets, despite few tilted and perpendicularly oriented nanoplatelets. Notably, typically applied post-printing processing, such as heat treatments, were not required to obtain well-adhered LDH films. In addition, the ink was binder- and dispersant-free, thus avoiding the presence of high molecular weight organics from the nanoplatelet synthesis to inkjet printing, which leads to direct inter-particle and particle-substrate interactions.

The adhesion of the LDH film was further investigated through the scotch tape test. Scotch tape was pressed on the LDH film and removed. Only a very weak detachment of the printed particles was observed confirming the strong interaction of the material with the substrate, likely enhanced by the preferential orientation of the nanoplatelets onto the glassy carbon when deposited as picoliter droplets of ink (Fig. S3). Therefore, the possibility to use the coated electrodes directly as-printed represents another advantage of the developed fabrication protocol.

Adjustable catalyst loadings and thus different film thicknesses were accurately realized by modifying the number of printed ink layers. For instance, extremely low loadings, such as 0.9 $\mu \mathrm{g} \cdot \mathrm{cm}^{-2}$ resulted in partial coverage of the GC substrate, while loadings above $11 \mu \mathrm{g} \cdot \mathrm{cm}^{-2}$ resulted in only a few uncovered spots (Fig.S3(a) and (b)). Loadings above $50 \mu \mathrm{g} \cdot \mathrm{cm}^{-2}$ resulted in compact 
LDH films with a preferentially aligned morphology, in which porosity cannot be seen from the SEM analysis (Fig. S4(c), Fig. 4c and vide infra). The cross-sectional analysis of the films with loadings of 50 and $150 \mu \mathrm{g} \cdot \mathrm{cm}^{-2}$ confirmed continuous and uniform film thicknesses of 140 and 450 nm, respectively (Fig. 4c and Fig. 4d). The measured ratio of 3.2 between the two thicknesses is in good agreement with the ratio of 3 between the two catalyst loadings (i.e., $50 \mu \mathrm{g} \cdot \mathrm{cm}^{-2}$ and $150 \mu \mathrm{g} \cdot \mathrm{cm}^{-2}$ ). Indeed, the possibility to cut, polish and observe the cross-section of the deposited LDH films on GC highlights further the strong interparticle and film adhesion to the GC substrate, despite the absence of binders and thermal treatments. 


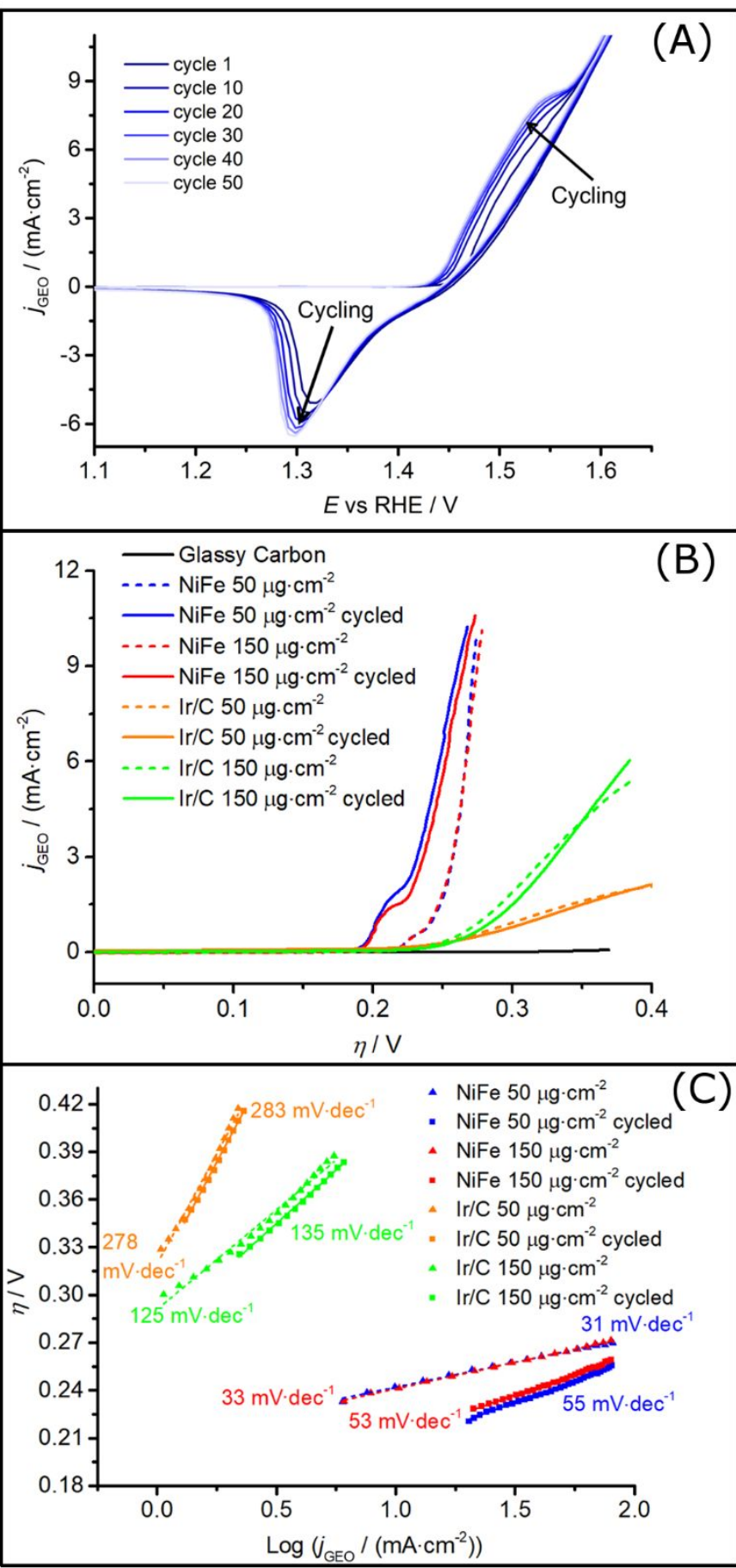

Figure 5. a) Cyclic voltammogram $\left(40 \mathrm{mV} \cdot \mathrm{s}^{-1}\right)$ of the $50 \mu \mathrm{g} \cdot \mathrm{cm}^{-2} \mathrm{NiFe} \mathrm{LDH}$ sample. b) Polarization curves $\left(5 \mathrm{mV} \cdot \mathrm{s}^{-1}\right)$ of the printed NiFe LDH- and Ir/C-coated electrodes with 50 and $150 \mu \mathrm{g} \cdot \mathrm{cm}^{-2}$ loadings, before and after activation/ageing. c) Tafel plot from the curves in (b). Data in (b) are iR-corrected, while data in (a) are reported without $i R$-correction. 
Thereafter, electrochemical characterization of the printed 2D Ni-Fe LDH nanoplatelet films was performed with these two catalyst loadings $\left(50 \mu \mathrm{g} \cdot \mathrm{cm}^{-2}\right.$ or $\left.150 \mu \mathrm{g} \cdot \mathrm{cm}^{-2}\right)$. The $2 \mathrm{D}$ planar structure of the inkjet-printed LDH films allowed characterizing the material electrochemically under consideration of the geometric surface area. With vertically aligned LDH-based electrodes or mesoporous structures, such as metal foam supported LDHs as often reported, the comparative analysis of materials requires the accurate determination of the electrochemically active surface area (ECSA). This can be challenging and often subject to errors. In contrast, the present fabrication method provides, therefore, a basis for facile and comparable characterization of flat and reproducible electrodes made of various LDH materials. Fig. 5a shows six exemplary cycles from the 50 -cycle based CV of the $50 \mu \mathrm{g} \cdot \mathrm{cm}^{-2}$ sample in $0.1 \mathrm{M} \mathrm{KOH}$. The plot shows the typical shape of Ni-Fe LDH CVs, which is a steep increase of the current corresponding to the OER partially overlapping with the oxidation peak of $\mathrm{Ni}^{2+}$ to $\mathrm{Ni}^{3+}$ at $\sim 1.55 \mathrm{~V}$. The electrochemical reduction from $\mathrm{Ni}^{3+}$ to $\mathrm{Ni}^{2+}$ can be seen clearly from a cathodic peak with onset at around $1.35 \mathrm{~V}$. Notably, both the oxidation peak for $\mathrm{Ni}^{2+}$ and the reduction peak for $\mathrm{Ni}^{3+}$ increased during cycling suggesting that a larger number of $\mathrm{Ni}^{2+}$ sites became accessible for the oxidation during cycling until a steady state was obtained. A similar behaviour is observed for Ni electrodes, where an increase in the $\mathrm{Ni}^{2+/ 3+}$ oxidation peak is attributed to the growing thickness of the nickel oxide surface layer ${ }^{62}$.

The onset potential for the OER was estimated by extrapolation and was between $1.43 \mathrm{~V}$ and 1.48 V (Fig. 5b). Due to its poor activity for the OER, the contribution from the GC support for the OER is negligible, as proven by measuring a GC electrode alone (Fig. 5b, black line). The comparison of the polarization curves $\left(5 \mathrm{mV} \cdot \mathrm{s}^{-1}\right)$ of Ni-Fe LDH films with the two different catalyst loadings $\left(50 \mu \mathrm{g} \cdot \mathrm{cm}^{-2}\right.$ or $\left.150 \mu \mathrm{g} \cdot \mathrm{cm}^{-2}\right)$ showed a remarkable overlap of the curves (Fig. 
5b). This indicates that the Ni-Fe LDH films (Fig. 4b) exhibited a full coverage of the substrate with nanoplatelets having a preferential orientation parallel to the substrate and low porosity and roughness. The alignment induced by the platelet morphology formed a closed microstructure for these two loadings, which suggests that the most superficial layers of the differently loaded films took equally part in the electrochemical reaction. Consequently, the electrodes with the two loadings behaved as a Ni-Fe LDH bulk 2D surface with activity that appeared independent from the film thickness. Inkjet printing of more films of the two loadings resulted in overlapping polarization curves demonstrating the repeatability of the printing process and film formation (two additional curves are provided in the supplementary information (Fig. S5)). Therefore, higher loadings could behave in the same way, as long as the film formation proceeds as compact as presented for the two loadings herein.

Another important aspect is the conductivity of the LDH films, as a low conductivity would influence negatively the electrochemical electrode performance creating large $i R$-drops. Increasing the thickness of the LDH film by a factor of three did not change the electrochemical response, indicating the absence or a minor contribution of a resistance in the LDH film, at least in the covered thickness range of hundreds of nanometers. For fresh samples, the overpotential at 10 $\mathrm{mA} \cdot \mathrm{cm}^{-2}$ (geometric electrode area) corresponded to $280 \mathrm{mV}$, while after potential cycling the overpotential was reduced to $270 \mathrm{mV}$ indicating a modification of the Ni-Fe LDH film. Also after cycling, the polarization curves for both Ni-Fe LDH loadings overlapped closely, indicating further the thickness-independent activity of the films with different thicknesses. The recorded overpotentials are in good agreement with previous measurements of Ni-Fe LDH coated electrodes reported in the literature (Table S1), ranging between 197 and $350 \mathrm{mV}$ at a current density of 10 
$\mathrm{mA} \cdot \mathrm{cm}^{-2}$. Generally, such comparisons must consider the different stoichiometries for the Ni-Fe LDH phases and varying catalyst supports.

The measured overpotentials of the herein presented Ni-Fe LDH films were higher than both the bare glassy carbon support and reference films of Ir/C-Nafion, which were inkjet-printed on GC with the same loadings as the Ni-Fe LDH samples. Nafion was used as a dispersion stabilizer for stable inkjet printing and as a binder to provide adhesion of the $\mathrm{Ir} / \mathrm{C}$-Nafion-film to the glassy carbon surface. The onset potential for the OER of the Ir/C-Nafion-coated electrodes was $\sim 1.48 \mathrm{~V}$ and therefore comparable with the inkjet-printed Ni-Fe LDH films. The Ir/C-Nafion films showed a significant dependence on the catalyst loading. Due to the mesoporosity induced by the presence of Nafion, the number of accessible active sites per area increased with each printed layer. Further, the Ir surface can be partially blocked by Nafion leading to particle-to-particle resistances and lowering possibly the Ir/C-Nafion film conductivity. Due to these facts, the overpotentials of both materials can herein not accurately be compared and $10 \mathrm{~mA} \cdot \mathrm{cm}^{-2}$ was not reached for Ir/C-Nafion in the applied potential range. However, it is important to point out that the $\mathrm{Ir} / \mathrm{C}-\mathrm{Nafion}$ catalyst films did not show a significant change in the shape and position of the polarization curves during the potential cycling process, compared to the Ni-Fe LDH films, which were subjected to a more impacting material change.

Fig. 5c reports the Tafel slopes calculated from the $i R$-corrected data in Fig. $\mathbf{5 b}$. The two Ni-Fe LDH loadings gave low Tafel slopes of $31-33 \mathrm{mV} \cdot \mathrm{dec}^{-1}$ before potential cycling and increased Tafel slopes of 53-55 $\mathrm{mV} \mathrm{dec}{ }^{-1}$ after cycling. On the contrary, Ir/C-Nafion did not show such a significant increase of the Tafel slope upon cycling, indicating again that the Ni-Fe LDH film was subject to a change of the material properties. As the change of the Tafel slope is generally correlated with a change in the limiting step of the OER, these changes influence the electrode 
kinetics and thus the rate limiting steps ${ }^{63}$. The slopes of non-activated Ni-Fe LDH samples are in agreement with previous experimental data from the literature (Table S1). These values rank among the lowest slopes reported. Microkinetic calculations ${ }^{64}$ related such a high catalytic activity to a reaction mechanism having a rate determining step corresponding to the first single electron transfer of the OER. This reaction model, indeed, displays a theoretical Tafel slope of $30 \mathrm{mV} \cdot \mathrm{dec}^{-1}$. An evaluation of the durability of the Ni-Fe LDH films was performed via a chronopotentiometric test for $3 \mathrm{~h}$ at a current density of $10 \mathrm{~mA} \cdot \mathrm{cm}^{-2}$ (Fig. S6). The potential presented an increase of ca. $30 \mathrm{mV}$ during the first $30 \mathrm{~min}$, followed by a decay rate of $\sim 7 \mathrm{mV} \cdot \mathrm{h}^{-1}$ during the remaining 2.5 hours (Fig. S6). This result indicates the presence of a degradation mechanism that requires further investigation in regard of the presented material synthesis and thin film deposition as OER electrocatalyst layer. Despite this observation, after the durability test, the compact LDH film was still on the GC surface and the nanoplatelet film appeared unchanged demonstrating the mechanical stability of the printed film (Fig. S7).

The electrochemical data clearly demonstrated the accurate production of low-loaded Ni-Fe LDH/GC electrodes with good and load-independent electrochemical performance. Potential cycling of the Ni-Fe LDH-based films reduced the overpotentials and increased the Tafel slopes. A similar behaviour was recently reported in literature by aging Ni-Fe LDH in strong alkaline solutions ${ }^{65}$. In that work the authors could show that a higher overpotential at large current densities and higher Tafel slope was correlated with a structural change of the LDH material (formation of $\mathrm{Ni}(\mathrm{OH})_{2}$ and $\mathrm{FeOOH}$ ). For OER in devices such as electrolysers, catalyst layers are usually mesoporous reaching high ECSAs. Such mesoporous films take advantage of a larger number of active sides per geometric electrode area and can be envisaged by printing the LDH 


\begin{abstract}
ink on mesoporous, conductive supports, such as common metal foams or structures of carbon nanofibers ${ }^{66}$ or graphene ${ }^{55}$.
\end{abstract}

\title{
Conclusions
}

To conclude, Ni-Fe LDH 2D nanoplatelets were reproducibly synthesized at large scale by CHFS and then accurately deposited with low loadings on large scale electrodes as highly efficient OER electrocatalyst. The scalable synthetic route limited the particle growth to $\sim 50 \mathrm{~nm}$ leading to waterborne dispersions with high potential for their conversion into inks for inkjet printing. The addition of iPA and 1,2-PG did not only adjust the viscosity and surface tension of the produced inks to reach optimal printability, it also increased the stability of the nanoplatelet colloid. The CHFS of the Ni-Fe LDH produced large amounts of materials in short time that, after minor adjustment of the carrier liquid, can be immediately printed while standard chemical methods for growing LDH on supports can take many hours.

Inkjet printing showed remarkable performances in the deposition of Ni-Fe LDH films with the capability of printing patterns with features as small as $44 \mu \mathrm{m}$ and continuous films as thin as $140 \mathrm{~nm}$, with material loadings in the $\mu \mathrm{m} \cdot \mathrm{cm}^{-2}$ range. Furthermore, the combination of inkjet printing and 2D particles led to an accurate assembling of the printed nanoplatelets, which oriented preferentially parallel to the substrate. This microstructure resulted, during electrochemical analysis, in a planar bulk LDH film behaviour of inkjet printed electrodes with two different loadings above $50 \mu \mathrm{m} \cdot \mathrm{cm}^{-2}$. In particular, the electrochemical performances of the inkjet-printed LDH nanoplatelet layers demonstrated an independency of the catalyst loading on the polarization curves suggesting that only the outmost layer of particles contributed to the OER. The performance of the Ni-Fe LDH films was superior to Ir/C-Nafion-coated electrodes that were printed with 
identical catalyst loadings, but long term film stability during OER operation should be further addressed. Major advantages of inkjet printing, besides achieving accurately ultralow material loadings and homogeneous coatings, can be attributed to the possibility of creating ultrathin micropatterned structures, which is of interest for material screening and miniaturized electrodes in portable devices.

The future possibility of combining the CHFS reactor directly with inkjet printing by implementing an intermediate ink formulation unit makes the presented approach very attractive for the large-scale production of coated electrodes. It can also be envisaged to apply the CHFS/inkjet printing concept to a much broader range of LDH materials and their composites.

\section{Supporting Information}

Supplementary material contains additional TEM images, the design of the printed electrode patterns, details on the scotch tape test, additional polarization curves, other tested ultra-low LDH loadings on GC, a comparison of the OER activity of the inkjet-printed Ni-Fe LDH electrode with other recently reported $\mathrm{Ni}-\mathrm{Fe} \mathrm{LDH}$ materials from literature, and details on the durability test of the inkjet-printed $\mathrm{NiFe} \mathrm{LDH} / \mathrm{GC}$ electrode.

\section{Acknowledgements}

This project has partially received funding from the Fuel Cells and Hydrogen 2 Joint Undertaking under grant agreement No 700266. This Joint Undertaking receives support from the European Union's Horizon 2020 research and innovation program and Hydrogen Europe and N.ERGHY. 
The authors also acknowledge funding from Swiss National Science Foundation through the Ambizione Energy Project No. 154297. A.L. acknowledges the support from the Italian Ministry of Education, Universities and Research (Ministero dell'Istruzione, dell'Università e della Ricerca - MIUR) through a “Rita Levi Montalcini” grant (N. PGR16DTCYB).

\section{Bibliography}

(1) Dusastre, V.; Arico', A. S.; Bruce, P.; SCrosati, B.; Tarascon, J. M.; Van Schalkwijk, W. Nanostructured Materials for Advanced Energy Conversion and Storage Devices. Mater. Sustain. Energy 2012, 4 (May), 148-159. https://doi.org/10.1142/9789814317665_0022.

(2) Tan, C.; Cao, X.; Wu, X. J.; He, Q.; Yang, J.; Zhang, X.; Chen, J.; Zhao, W.; Han, S.; Nam, G. H.; et al. Recent Advances in Ultrathin Two-Dimensional Nanomaterials. Chem. Rev. 2017, 117 (9), 6225-6331. https://doi.org/10.1021/acs.chemrev.6b00558.

(3) Jin, H.; Guo, C.; Liu, X.; Liu, J.; Vasileff, A.; Jiao, Y.; Zheng, Y.; Qiao, S. Z. Emerging Two-Dimensional Nanomaterials for Electrocatalysis. Chem. Rev. 2018, 118 (13), 63376408. https://doi.org/10.1021/acs.chemrev.7b00689.

(4) Cai, Z.; Bu, X.; Wang, P.; Ho, J. C.; Yang, J.; Wang, X. Recent Advances in Layered Double Hydroxide Electrocatalysts for the Oxygen Evolution Reaction. J. Mater. Chem. A 2019, 7 (10), 5069-5089. https://doi.org/10.1039/c8ta11273h.

(5) Uzunova, E.; Klissurski, D.; Kassabov, S. Nickel-Iron Hydroxide Carbonate Precursors in the Synthesis of High-dispersity Oxides. J. Mat. Chem. 1994, 4 (1), 153-159.

(6) Xu, Z. P.; Zhang, J.; Adebajo, M. O.; Zhang, H.; Zhou, C. Catalytic Applications of Layered Double Hydroxides and Derivatives. Appl. Clay Sci. 2011, 53 (2), 139-150. https://doi.org/10.1016/j.clay.2011.02.007.

(7) Liu, Y.; Liang, X.; Gu, L.; Zhang, Y.; Li, G. D.; Zou, X.; Chen, J. S. Corrosion Engineering towards Efficient Oxygen Evolution Electrodes with Stable Catalytic Activity for over 6000 Hours. Nat. Commun. 2018, 9 (1), 1-10. https://doi.org/10.1038/s41467018-05019-5.

(8) Gong, M.; Li, Y.; Wang, H.; Liang, Y.; Wu, J. Z.; Zhou, J.; Wang, J.; Regier, T.; Wei, F.; Dai, H. An Advanced Ni-Fe Layered Double Hydroxide Electrocatalyst for Water Oxidation. J. Am. Chem. Soc. 2013, 135 (23), 8452-8455. https://doi.org/10.1021/ja4027715. 
(9) Gao, Z. W.; Liu, J. Y.; Chen, X. M.; Zheng, X. L.; Mao, J.; Liu, H.; Ma, T.; Li, L.; Wang, W. C.; Du, X. W. Engineering NiO/NiFe LDH Intersection to Bypass Scaling Relationship for Oxygen Evolution Reaction via Dynamic Tridimensional Adsorption of Intermediates. Adv. Mater. 2019, 31 (11), 1-8. https://doi.org/10.1002/adma.201804769.

(10) Deng, X.; Huang, J.; Wan, H.; Chen, F.; Lin, Y.; Xu, X.; Ma, R.; Sasaki, T. Recent Progress in Functionalized Layered Double Hydroxides and Their Application in Efficient Electrocatalytic Water Oxidation. J. Energy Chem. 2019, 32, 93-104. https://doi.org/10.1016/j.jechem.2018.07.007.

(11) McCrory, C. C. L.; Jung, S.; Peters, J. C.; Jaramillo, T. F. Benchmarking Heterogeneous Electrocatalysts for the Oxygen Evolution Reaction. J. Am. Chem. Soc. 2013, 135 (45), 16977-16987. https://doi.org/10.1021/ja407115p.

(12) Gong, M.; Dai, H. A Mini Review of NiFe-Based Materials as Highly Active Oxygen Evolution Reaction Electrocatalysts. Nano Res. 2014, 8 (1), 23-39. https://doi.org/10.1007/s12274-014-0591-z.

(13) Wang, Q.; Shang, L.; Shi, R.; Zhang, X.; Zhao, Y.; Waterhouse, G. I. N.; Wu, L. Z.; Tung, C. H.; Zhang, T. NiFe Layered Double Hydroxide Nanoparticles on Co,N-Codoped Carbon Nanoframes as Efficient Bifunctional Catalysts for Rechargeable Zinc-Air Batteries. Adv. Energy Mater. 2017, 7 (21), 1-7. https://doi.org/10.1002/aenm.201700467.

(14) Zhu, W.; Liu, L.; Yue, Z.; Zhang, W.; Yue, X.; Wang, J.; Yu, S.; Wang, L.; Wang, J. Au Promoted Nickel-Iron Layered Double Hydroxide Nanoarrays: A Modular Catalyst Enabling High-Performance Oxygen Evolution. ACS Appl. Mater. Interfaces 2017, 9 (23), 19807-19814. https://doi.org/10.1021/acsami.7b03033.

(15) Wang, Y.; Qiao, M.; Li, Y.; Wang, S. Tuning Surface Electronic Configuration of NiFe LDHs Nanosheets by Introducing Cation Vacancies (Fe or Ni) as Highly Efficient Electrocatalysts for Oxygen Evolution Reaction. Small 2018, 14 (17), 1-6. https://doi.org/10.1002/smll.201800136.

(16) Li, J. G.; Sun, H.; Lv, L.; Li, Z.; Ao, X.; Xu, C.; Li, Y.; Wang, C. Metal-Organic Framework-Derived Hierarchical (Co,Ni)Se $2 @ N i F e$ LDH Hollow Nanocages for Enhanced Oxygen Evolution. ACS Appl. Mater. Interfaces 2019, 11 (8), 8106-8114. https://doi.org/10.1021/acsami.8b22133.

(17) Pallas, G.; Peijnenburg, W. J. G. M.; Guinée, J. B.; Heijungs, R.; Vijver, M. G. Green and Clean: Reviewing the Justification of Claims for Nanomaterials from a Sustainability Point of View. Sustain. 2018, 10 (3). https://doi.org/10.3390/su10030689.

(18) Petosa, A. R.; Jaisi, D. E. B. P.; Quevedo, I. R.; Elimelech, M. Aggregation and Deposition of Engineered Nanomaterials in Aquatic Environments: Role of Physicochemical Interactions. 2010, 44 (17), 6532-6549. https://doi.org/10.1021/es100598h.

(19) Stavis, S. M.; Fagan, J. A.; Stopa, M.; Liddle, J. A. Nanoparticle Manufacturing Heterogeneity through Processes to Products. ACS Appl. Nano Mater. 2018, 1 (9), 43584385. https://doi.org/10.1021/acsanm.8b01239. 
(20) Darr, J. A.; Zhang, J.; Makwana, N. M.; Weng, X. Continuous Hydrothermal Synthesis of Inorganic Nanoparticles: Applications and Future Directions. Chem. Rev. 2017, 117 (17), 11125-11238. https://doi.org/10.1021/acs.chemrev.6b00417.

(21) OHare, D.; Wang, Q.; Tang, S.; Lester, E. Synthesis of Ultrafine Layered Double Hydroxide (LDHs) Nanoparticles Using a Continuous-Flow Hydrothermal Reactor. Nanoscale 2012, 114-117. https://doi.org/10.1039/c2nr32568c.

(22) Clark, I.; Dunne, P. W.; Gomes, R. L.; Lester, E. Continuous Hydrothermal Synthesis of Ca2Al-NO3layered Double Hydroxides: The Impact of Reactor Temperature, Pressure and $\mathrm{NaOH}$ Concentration on Crystal Characteristics. J. Colloid Interface Sci. 2017, 504 (3), 492-499. https://doi.org/10.1016/j.jcis.2017.05.105.

(23) Adschiri, T.; Hakuta, Y.; Sue, K.; Arai, K. Hydrothermal Synthesis of Metal Oxide Nanoparticles at Supercritical Conditions. J. Nanoparticle Res. 2001, 3, 227-235. https://doi.org/10.1023/A:1017541705569.

(24) Tichit, D.; Layrac, G.; Gérardin, C. Synthesis of Layered Double Hydroxides through Continuous Flow Processes: A Review. Chem. Eng. J. 2019, 369 (March), 302-332. https://doi.org/10.1016/j.cej.2019.03.057.

(25) Lee, S.; Cho, H.-S.; Cho, W.-C.; Kim, S.-K.; Cho, Y.; Kim, C.-H. Operational Durability of Three-Dimensional Ni-Fe Layered Double Hydroxide Electrocatalyst for Water Oxidation. Electrochim. Acta 2019. https://doi.org/10.1016/j.electacta.2019.05.088.

(26) Sun, W.; Du, L.; Du, C.; Gao, Y.; Yin, G. Three-Dimensional Layered Double Hydroxides on Carbon Nanofibers: The Engineered Mass Transfer Channels and Active Sites towards Oxygen Evolution Reaction. Appl. Surf. Sci. 2019, 485, 41-47. https://doi.org/10.1016/j.apsusc.2019.03.335.

(27) Zhang, H.; Li, H.; Akram, B.; Wang, X. Fabrication of NiFe Layered Double Hydroxide with Well-Defined Laminar Superstructure as Highly Efficient Oxygen Evolution Electrocatalysts. Nano Res. 2019. https://doi.org/10.1007/s12274-019-2284-0.

(28) Scavetta, E.; Vlamidis, Y.; Posati, T.; Nocchetti, M.; Tonelli, D. Effect of the Synthesis Route and Fe Presence on the Redox Activity of Ni in Layered Double Hydroxides. ChemElectroChem 2016, 3 (9), 1320-1328. https://doi.org/10.1002/celc.201600197.

(29) Rosa, M.; Gooden, P. N.; Butterworth, S.; Zielke, P.; Kiebach, R.; Xu, Y.; Gadea, C.; Esposito, V. Zirconia Nano-Colloids Transfer from Continuous Hydrothermal Synthesis to Inkjet Printing. J. Eur. Ceram. Soc. 2017, No. July, 0-6. https://doi.org/10.1016/j.jeurceramsoc.2017.11.035.

(30) Rosa, M.; Zielke, P.; Kiebach, R.; Costa Bassetto, V.; Lesch, A.; Esposito, V. Printing of NiO-YSZ Nanocomposites: From Continuous Synthesis to Inkjet Deposition. J. Eur. Ceram. Soc. 2019, 39 (4), 1279-1286. https://doi.org/10.1016/j.jeurceramsoc.2018.12.030.

(31) Reis, N.; Derby, B. Ink Jet Deposition of Ceramic Suspensions: Experiments of Droplet Formation. Mater. Res. 2000, 625, 117-122. https://doi.org/dx.doi.org/10.1557/PROC624-65. 
(32) Lesch, A. Print-Light-Synthesis of Platinum Nanostructured Indium-Tin-Oxide Electrodes for Energy Research. Adv. Mater. Technol. 2018, 3 (2), 1-10.

https://doi.org/10.1002/admt.201700201.

(33) Bonaccorso, F.; Bartolotta, A.; Coleman, J. N.; Backes, C. 2D-Crystal-Based Functional Inks. Adv. Mater. 2016, 6136-6166. https://doi.org/10.1002/adma.201506410.

(34) He, P.; Derby, B. Controlling Coffee Ring Formation during Drying of Inkjet Printed 2D Inks. Adv. Mater. Interfaces 2017, 4 (22), 2-7. https://doi.org/10.1002/admi.201700944.

(35) Carey, T.; Cacovich, S.; Divitini, G.; Ren, J.; Mansouri, A.; Kim, J. M.; Wang, C.; Ducati, C.; Sordan, R.; Torrisi, F. Fully Inkjet-Printed Two-Dimensional Material Field-Effect Heterojunctions for Wearable and Textile Electronics. Nat. Commun. 2017, 8 (1). https://doi.org/10.1038/s41467-017-01210-2.

(36) Worsley, R.; Pimpolari, L.; McManus, D.; Ge, N.; Ionescu, R.; Wittkopf, J. A.; Alieva, A.; Basso, G.; Macucci, M.; Iannaccone, G.; et al. All-2D Material Inkjet-Printed Capacitors: Toward Fully Printed Integrated Circuits. ACS Nano 2019, 13 (1), 54-60. https://doi.org/10.1021/acsnano.8b06464.

(37) McManus, D.; Vranic, S.; Withers, F.; Sanchez-Romaguera, V.; Macucci, M.; Yang, H.; Sorrentino, R.; Parvez, K.; Son, S. K.; Iannaccone, G.; et al. Water-Based and Biocompatible 2D Crystal Inks for All-Inkjet-Printed Heterostructures. Nat. Nanotechnol. 2017, 12 (4), 343-350. https://doi.org/10.1038/nnano.2016.281.

(38) Zhang, C. (John); McKeon, L.; Kremer, M. P.; Park, S. H.; Ronan, O.; Seral-Ascaso, A.; Barwich, S.; Coileáin, C.; McEvoy, N.; Nerl, H. C.; et al. Additive-Free MXene Inks and Direct Printing of Micro-Supercapacitors. Nat. Commun. 2019, 10 (1), 1-9. https://doi.org/10.1038/s41467-019-09398-1.

(39) Costa Bassetto, V.; Xiao, J.; Oveisi, E.; Amstutz, V.; Liu, B.; Girault, H. H.; Lesch, A. Rapid Inkjet Printing of High Catalytic Activity Co3O4/N-RGO Layers for Oxygen Reduction Reaction. Appl. Catal. A Gen. 2018, 563 (June), 9-17. https://doi.org/10.1016/j.apcata.2018.06.026.

(40) Costa Bassetto, V.; Mensi, M.; Oveisi, E.; Girault, H. H.; Lesch, A. Print-Light-Synthesis of $\mathrm{Ni}$ and $\mathrm{NiFe}-\mathrm{Nanoscale}$ Catalysts for Oxygen Evolution. ACS Appl. Energy Mater. 2019, 2, 6322-6331. https://doi.org/10.1021/acsaem.9b00957.

(41) Zielke, P.; Xu, Y.; Simonsen, S. B.; Norby, P.; Kiebach, R. Simulation, Design and Proofof-Concept of a Two-Stage Continuous Hydrothermal Flow Synthesis Reactor for Synthesis of Functionalized Nano-Sized Inorganic Composite Materials. J. Supercrit. Fluids 2016, 117, 1-12. https://doi.org/10.1016/j.supflu.2016.06.008.

(42) Rosa, M.; Marani, D.; Perin, G.; Simonsen, S. B.; Zielke, P.; Glisenti, A. Impact of Cation Redox Chemistry on Continuous Hydrothermal Synthesis of 2D-Ni(Co/Fe) Hydroxides. React. Chem. Eng. 2019, 18-20. https://doi.org/10.1039/c9re00334g.

(43) Derby, B. Inkjet Printing Ceramics : From Drops to Solid. 2011, 31, 2543-2550. https://doi.org/10.1016/j.jeurceramsoc.2011.01.016.

(44) Schneider, C. A.; Rasband, W. S.; Eliceiri, K. W. NIH Image to Image J: 25 Years of 
Image Analysis. Nat. Methods 2012, 9 (7), 671-675. https://doi.org/10.1038/nmeth.2089.

(45) Evans, D. G.; Slade, R. C. T. Structural Aspects of Layered Double Hydroxides. Struct. Bond. 2006, 119 (December 2005), 1-87. https://doi.org/10.1007/430_005.

(46) Wang, Y.; Zhang, Y.; Liu, Z.; Xie, C.; Feng, S.; Liu, D.; Shao, M.; Wang, S. Layered Double Hydroxide Nanosheets with Multiple Vacancies Obtained by Dry Exfoliation as Highly Efficient Oxygen Evolution Electrocatalysts. Angew. Chemie - Int. Ed. 2017, 56 (21), 5867-5871. https://doi.org/10.1002/anie.201701477.

(47) Forticaux, A.; Dang, L.; Liang, H.; Jin, S. Controlled Synthesis of Layered Double Hydroxide Nanoplates Driven by Screw Dislocations. Nano Lett. 2015, 15 (5), 34033409. https://doi.org/10.1021/acs.nanolett.5b00758.

(48) Song, F.; Hu, X. Exfoliation of Layered Double Hydroxides for Enhanced Oxygen Evolution Catalysis. Nat. Commun. 2014, 5, 1-9. https://doi.org/10.1038/ncomms5477.

Yu, J.; Wang, Q.; O’Hare, D.; Sun, L. Preparation of Two Dimensional Layered Double Hydroxide Nanosheets and Their Applications. Chem. Soc. Rev. 2017, 46, 5950-5974. https://doi.org/10.1039/C7CS00318H.

(50) Liang, H.; Meng, F.; Cabán-Acevedo, M.; Li, L.; Forticaux, A.; Xiu, L.; Wang, Z.; Jin, S. Hydrothermal Continuous Flow Synthesis and Exfoliation of NiCo Layered Double Hydroxide Nanosheets for Enhanced Oxygen Evolution Catalysis. Nano Lett. 2015, 15 (2), 1421-1427. https://doi.org/10.1021/nl504872s.

(51) Bru, P.; Brunel, L.; Buron, H.; Cayré, I.; Ducarre, X.; Fraux, A.; Mengual, O.; Meunier, G.; de Sainte Marie, A.; Snabre, P. Particle Size and Rapid Stability Analyses of Concentrated Dispersions: Use of Multiple Light Scattering Technique. 2009, 45-60. https://doi.org/10.1021/bk-2004-0881.ch003.

(52) Hutchings, I. M.; Martin, G. D. Inkjet Technology for Digital Fabrication; 2012. https://doi.org/10.1002/9781118452943.

(53) Wei, Y.; Chen, S.; Li, F.; Lin, Y.; Zhang, Y.; Liu, L. Highly Stable and Sensitive PaperBased Bending Sensor Using Silver Nanowires/Layered Double Hydroxides Hybrids. ACS Appl. Mater. Interfaces 2015, 7 (26), 14182-14191. https://doi.org/10.1021/acsami.5b03824.

(54) Lu, Y.; Jiang, B.; Fang, L.; Ling, F.; Wu, F.; Hu, B.; Meng, F.; Niu, K.; Lin, F.; Zheng, H. An Investigation of Ultrathin Nickel-Iron Layered Double Hydroxide Nanosheets Grown on Nickel Foam for High-Performance Supercapacitor Electrodes. J. Alloys Compd. 2017, 714, 63-70. https://doi.org/10.1016/j.jallcom.2017.04.197.

(55) Guo, W.; Yu, C.; Li, S.; Yang, J.; Liu, Z.; Zhao, C.; Huang, H.; Zhang, M.; Han, X.; Niu, Y.; et al. High-Stacking-Density, Superior-Roughness LDH Bridged with Vertically Aligned Graphene for High-Performance Asymmetric Supercapacitors. Small 2017, 13 (37), 1-9. https://doi.org/10.1002/smll.201701288.

(56) Beidaghi, M.; Wang, C. Micro-Supercapacitors Based on Interdigital Electrodes of Reduced Graphene Oxide and Carbon Nanotube Composites with Ultrahigh Power Handling Performance. Adv. Funct. Mater. 2012, 22 (21), 4501-4510. 
https://doi.org/10.1002/adfm.201201292.

(57) Scarpellini, D.; Leonardi, C.; Mattoccia, A.; Di Giamberardino, L.; Medaglia, P. G.; Mantini, G.; Gatta, F.; Giovine, E.; Foglietti, V.; Falconi, C.; et al. Solution-Grown Zn/Al Layered Double Hydroxide Nanoplatelets onto Al Thin Films: Fine Control of Position and Lateral Thickness. J. Nanomater. 2015, 2015 (1), 1-9. https://doi.org/10.1155/2015/809486.

(58) Yao, F.; Hu, H.; Xu, S.; Huo, R.; Zhao, Z.; Zhang, F.; Xu, F. Preparation and Regulating Cell Adhesion of Anion-Exchangeable Layered Double Hydroxide Micropatterned Arrays. ACS Appl. Mater. Interfaces 2015, 7 (7), 3882-3887. https://doi.org/10.1021/acsami.5b00145.

(59) Newhouse, P. F.; Boyd, D. A.; Shinde, A.; Guevarra, D.; Zhou, L.; Soedarmadji, E.; Li, G.; Neaton, J. B.; Gregoire, J. M. Solar Fuel Photoanodes Prepared by Inkjet Printing of Copper Vanadates. J. Mater. Chem. A 2016, 4 (19), 7483-7494. https://doi.org/10.1039/c6ta01252c.

(60) Fujimura, T.; Hikima, W.; Fukunaka, Y.; Homma, T. Analysis of the Effect of Surface Wettability on Hydrogen Evolution Reaction in Water Electrolysis Using Micro-Patterned Electrodes. Electrochem. commun. 2019, 101 (December 2018), 43-46. https://doi.org/10.1016/j.elecom.2019.02.018.

(61) Yin, J.; Li, Y.; Lv, F.; Lu, M.; Sun, K.; Wang, W.; Wang, L.; Cheng, F.; Li, Y.; Xi, P.; et al. Oxygen Vacancies Dominated NiS $2 /$ CoS 2 Interface Porous Nanowires for Portable Zn-Air Batteries Driven Water Splitting Devices. Adv. Mater. 2017, 29 (47), 1-8. https://doi.org/10.1002/adma.201704681.

(62) Görlin, M.; Chernev, P.; De Araújo, J. F.; Reier, T.; Dresp, S.; Paul, B.; Krähnert, R.; Dau, H.; Strasser, P. Oxygen Evolution Reaction Dynamics, Faradaic Charge Efficiency, and the Active Metal Redox States of Ni-Fe Oxide Water Splitting Electrocatalysts. J. Am. Chem. Soc. 2016, 138 (17), 5603-5614. https://doi.org/10.1021/jacs.6b00332.

(63) Miller, E. L. Electrochemical Behavior of Reactively Sputtered Iron-Doped Nickel Oxide. J. Electrochem. Soc. 2006, 144 (9), 3072. https://doi.org/10.1149/1.1837961.

(64) Shinagawa, T.; Garcia-Esparza, A. T.; Takanabe, K. Insight on Tafel Slopes from a Microkinetic Analysis of Aqueous Electrocatalysis for Energy Conversion. Sci. Rep. 2015, 5 (May), 1-21. https://doi.org/10.1038/srep13801.

(65) Andronescu, C.; Seisel, S.; Wilde, P.; Barwe, S.; Masa, J.; Chen, Y. T.; Ventosa, E.; Schuhmann, W. Influence of Temperature and Electrolyte Concentration on the Structure and Catalytic Oxygen Evolution Activity of Nickel-Iron Layered Double Hydroxide. Chem. - A Eur. J. 2018, 24 (52), 13773-13777. https://doi.org/10.1002/chem.201803165.

(66) Wang, F.; Wang, T.; Sun, S.; Xu, Y.; Yu, R.; Li, H. One-Step Synthesis of Nickle IronLayered Double Hydroxide/Reduced Graphene Oxide/Carbon Nanofibres Composite as Electrode Materials for Asymmetric Supercapacitor. Sci. Rep. 2018, 8 (1), 1-10. https://doi.org/10.1038/s41598-018-27171-0. 
1. Continuous synthesis

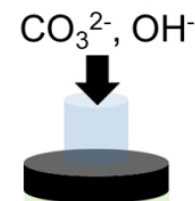

\section{Inkjet printing}

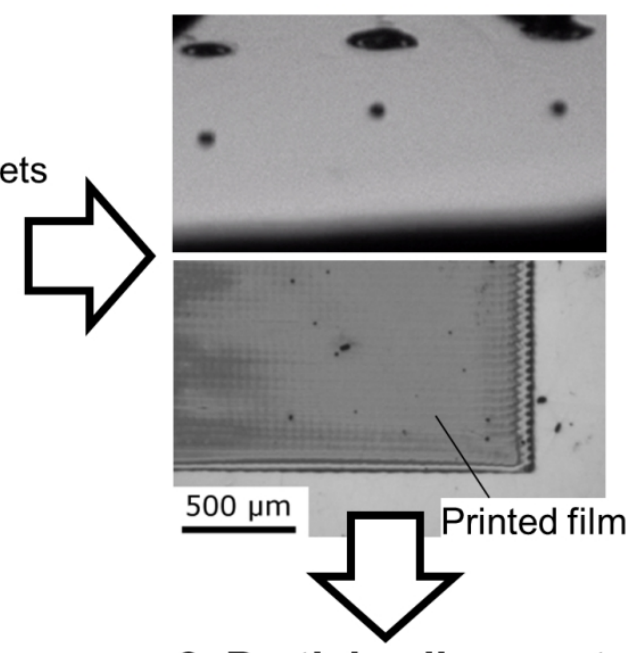

4. Electrochemical test

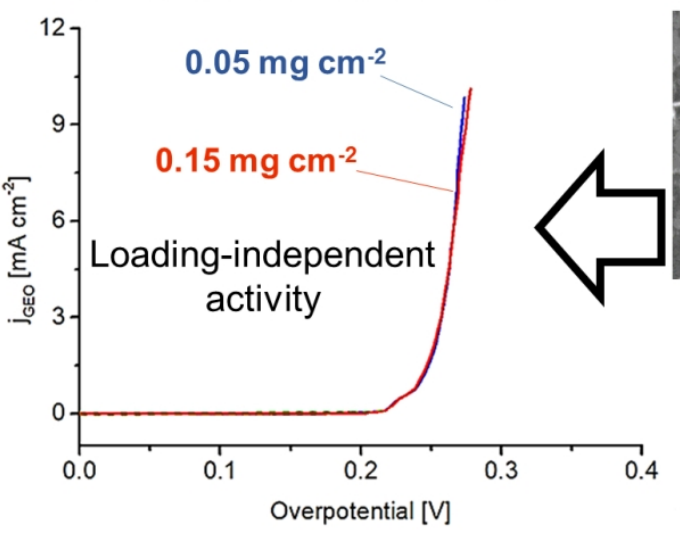

3. Particle alignment

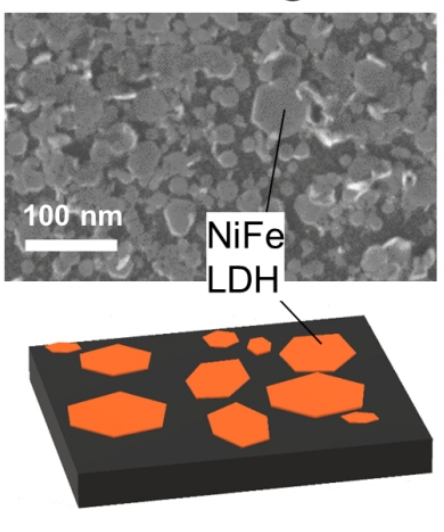

Graphical Abstract 

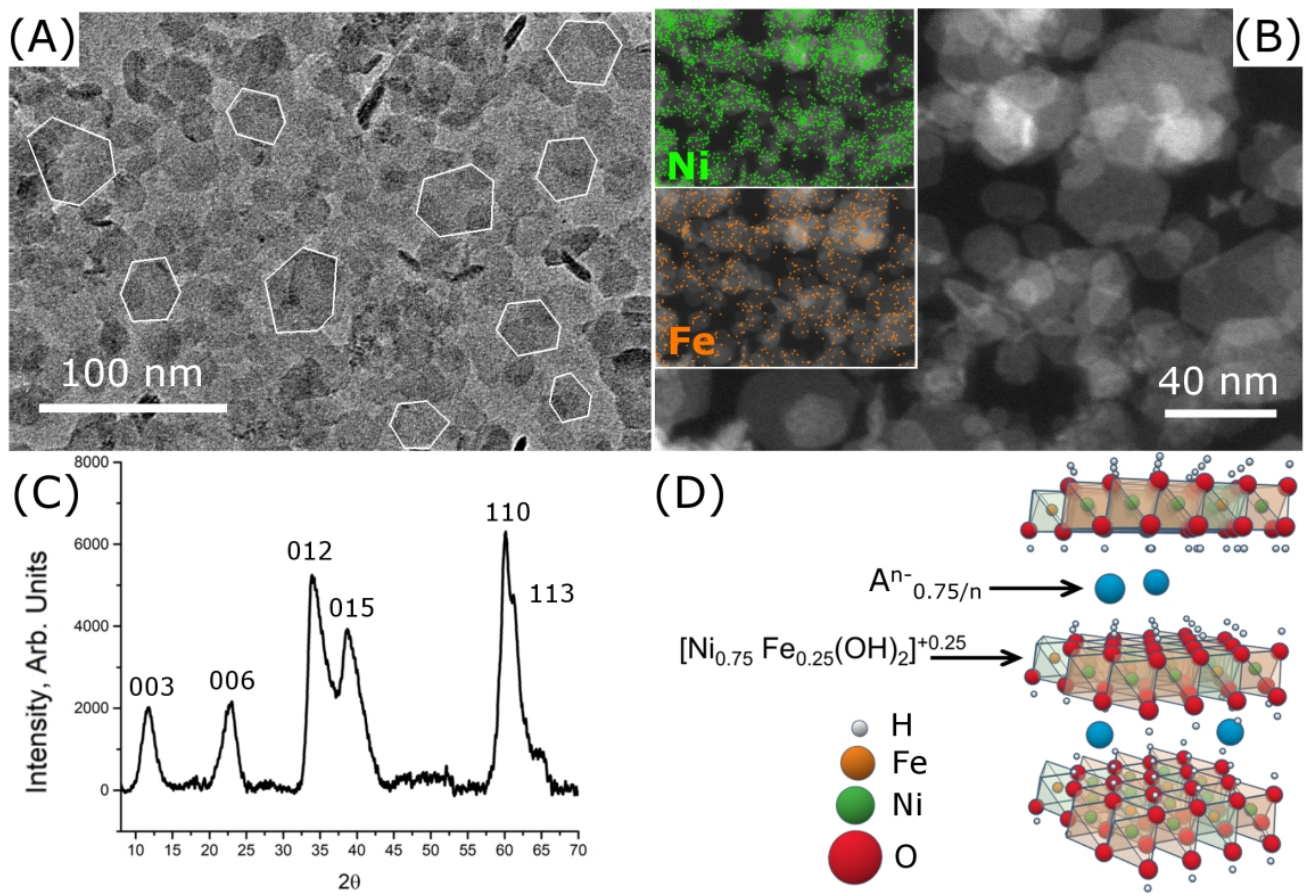

(D)

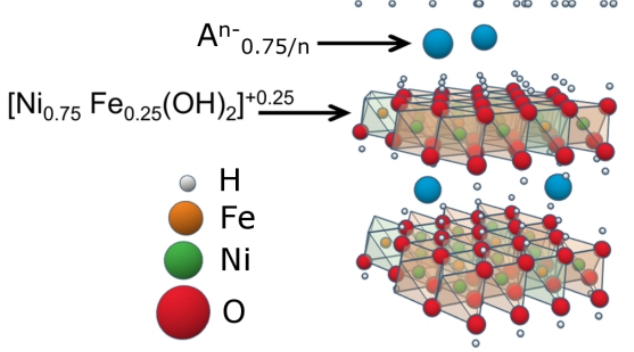

Figure 1. a) BF-TEM image of the as-produced $\mathrm{Ni}$-Fe LDH nanoplatelets (white lines around 10 exemplary nanoplates were added as guides to the eye), b) STEM image with EDX mapping shows $\mathrm{Ni}$ and Fe distribution in the insets, c) powder XRD pattern and d) model of the structure based on the data collected. $A^{n-}$ represents the intercalating anions for compensating the positive charge of the hydroxide layers. Due to the precursor composition, $\mathrm{A}^{\mathrm{n}-}$ consists of $\mathrm{NO}_{3}{ }^{-}$and $\mathrm{CO}_{3}{ }^{2-}$.

$694 \times 527 \mathrm{~mm}(76 \times 76 \mathrm{DPI})$ 


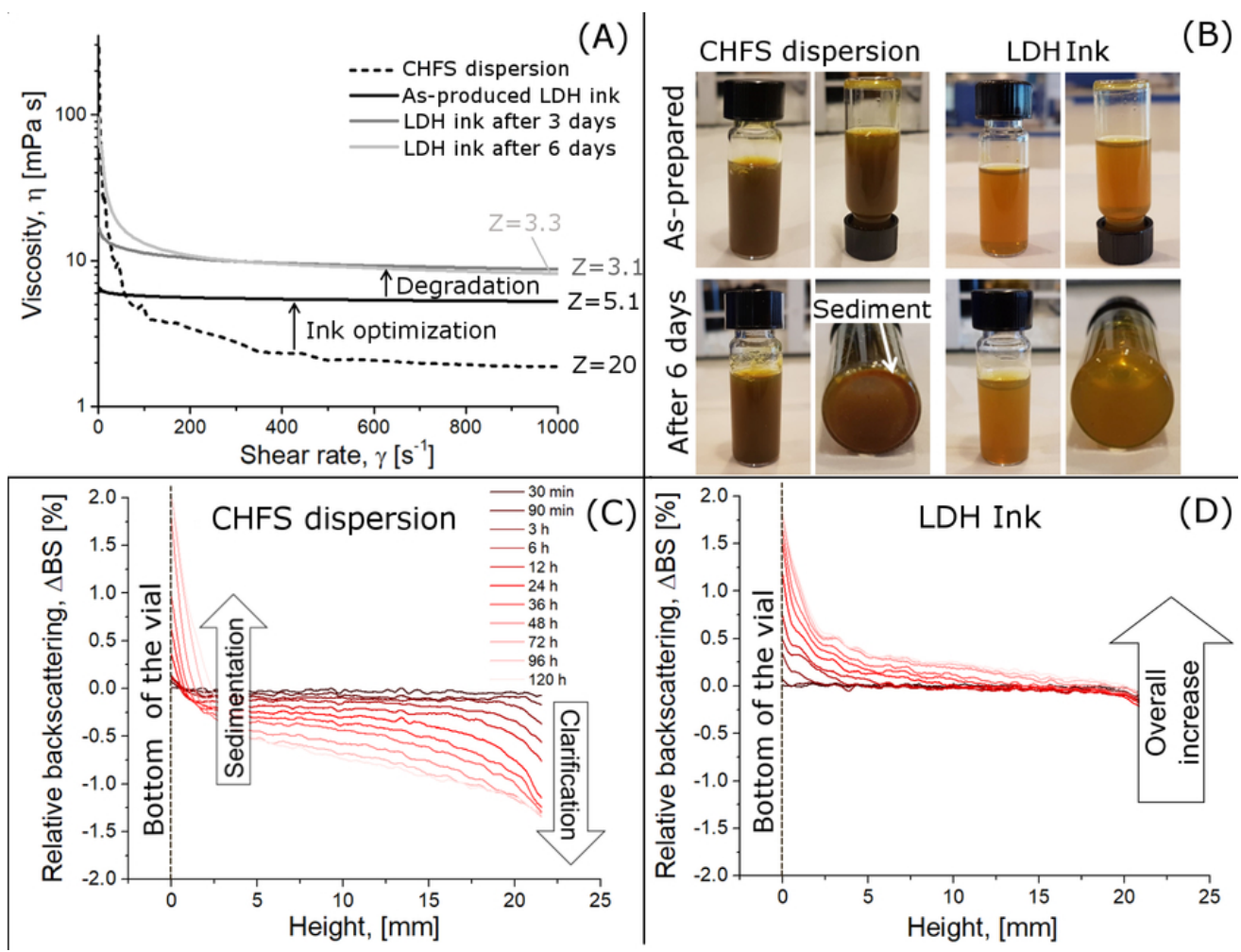

Figure 2. a) Flow curves of the CHFS dispersion (black, dashed), the just-prepared LDH ink (black, solid) and the LDH ink after 3 and 6 days on the shelf (greyscale). b) Photographs of the CHFS dispersion (left panels) and LDH ink (right panels) as-prepared (upper panels) and after 6 days on the shelf (lower panels). Colloidal stability analysis by static light scattering of the CHFS dispersion (c) and LDH ink (d).

\section{$77 \times 58 \mathrm{~mm}(300 \times 300$ DPI $)$}



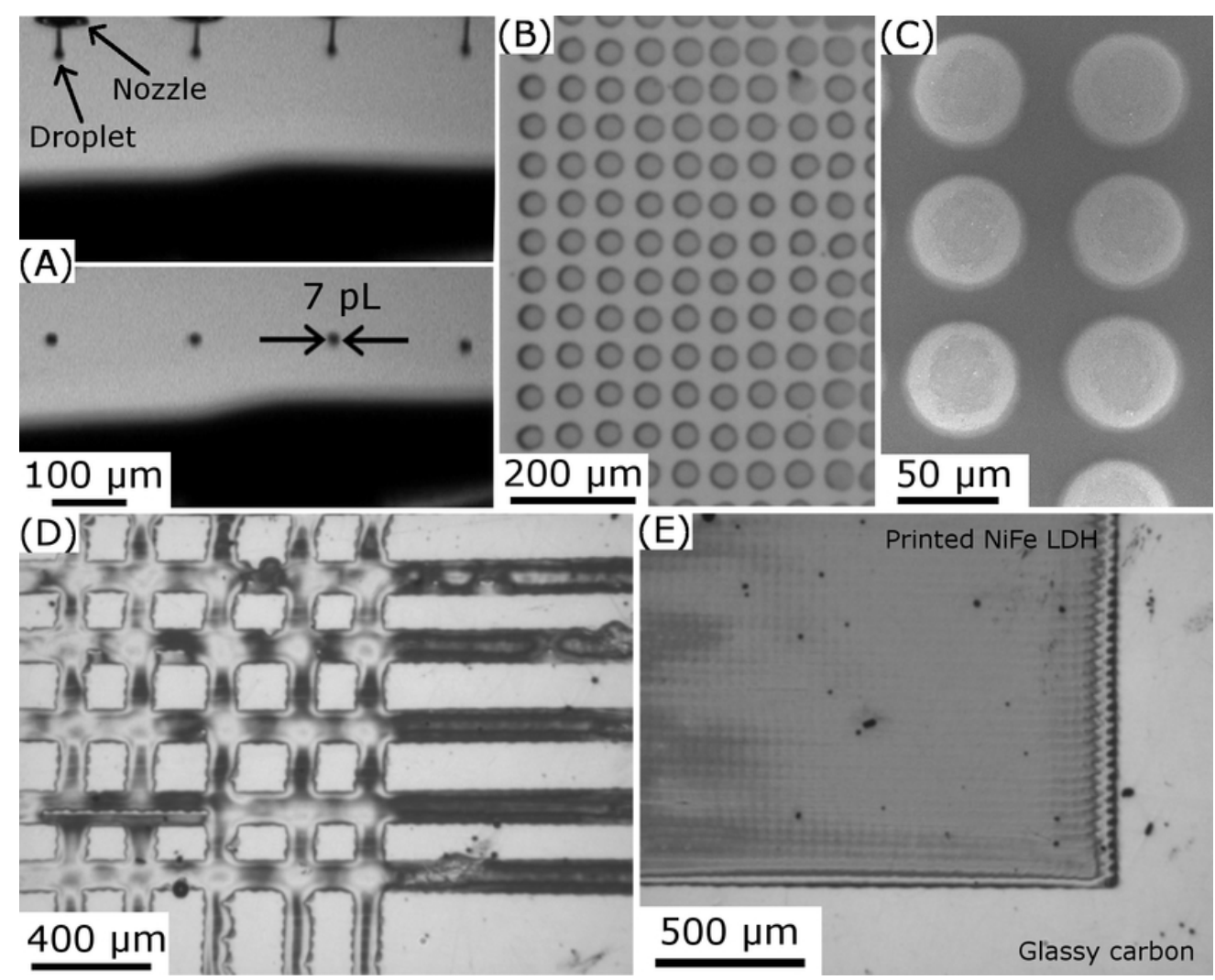

Printed NiFe LDH

Figure 3. Jetting and printing behaviour of the Ni-Fe LDH ink. a) Droplet ejection and formation from four exemplary adjacent nozzles (up: droplets being just expelled from the nozzles, thus, showing a tail; down: spherical, tail-free droplets during flight), b) printed droplet array onto glassy carbon, c) SEM image of separated splats (i.e., LDH ink droplets on the substrate) after solvent evaporation. d) An exemplary grid pattern of printed LDH ink onto glassy carbon, e) full coverage film printed onto glassy carbon with a particle loading of $70 \mu \mathrm{g} \cdot \mathrm{cm}^{-2}$. Note: the dark spots in (b) and (e) are features from the GC surface. In all cases, the printing direction was from left to right.

$69 \times 56 \mathrm{~mm}(300 \times 300$ DPI $)$ 

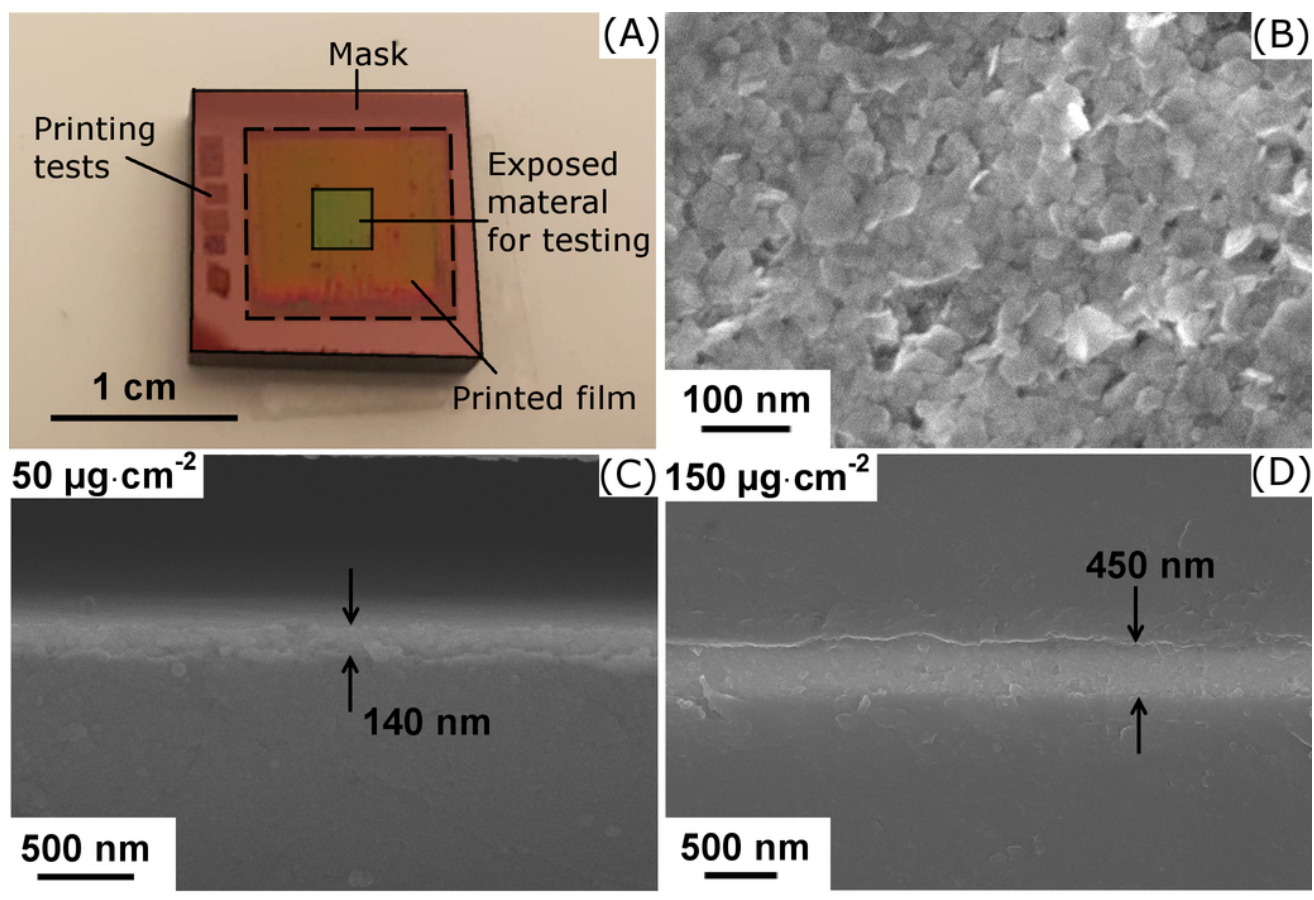

Figure 4. a) Exemplary printed electrode for electrochemical analysis with inkjet-printed $\mathrm{Ni}-\mathrm{Fe}$ LDH pattern (dashed line), masking area (red shadowed area with solid lines) and working electrode area (greenish appearing square in the centre). b) SEM image of the microstructure of the as-printed $\mathrm{Ni}-\mathrm{Fe}$ LDH nanoplatelets. Cross-sections of the printed Ni-Fe LDH films on glassy carbon plates with $50 \mu \mathrm{g} \cdot \mathrm{cm}^{-2}$ loading (c) and $150 \mu \mathrm{g} \cdot \mathrm{cm}^{-2}(\mathrm{~d})$.

$87 \times 59 \mathrm{~mm}(300 \times 300$ DPI $)$ 


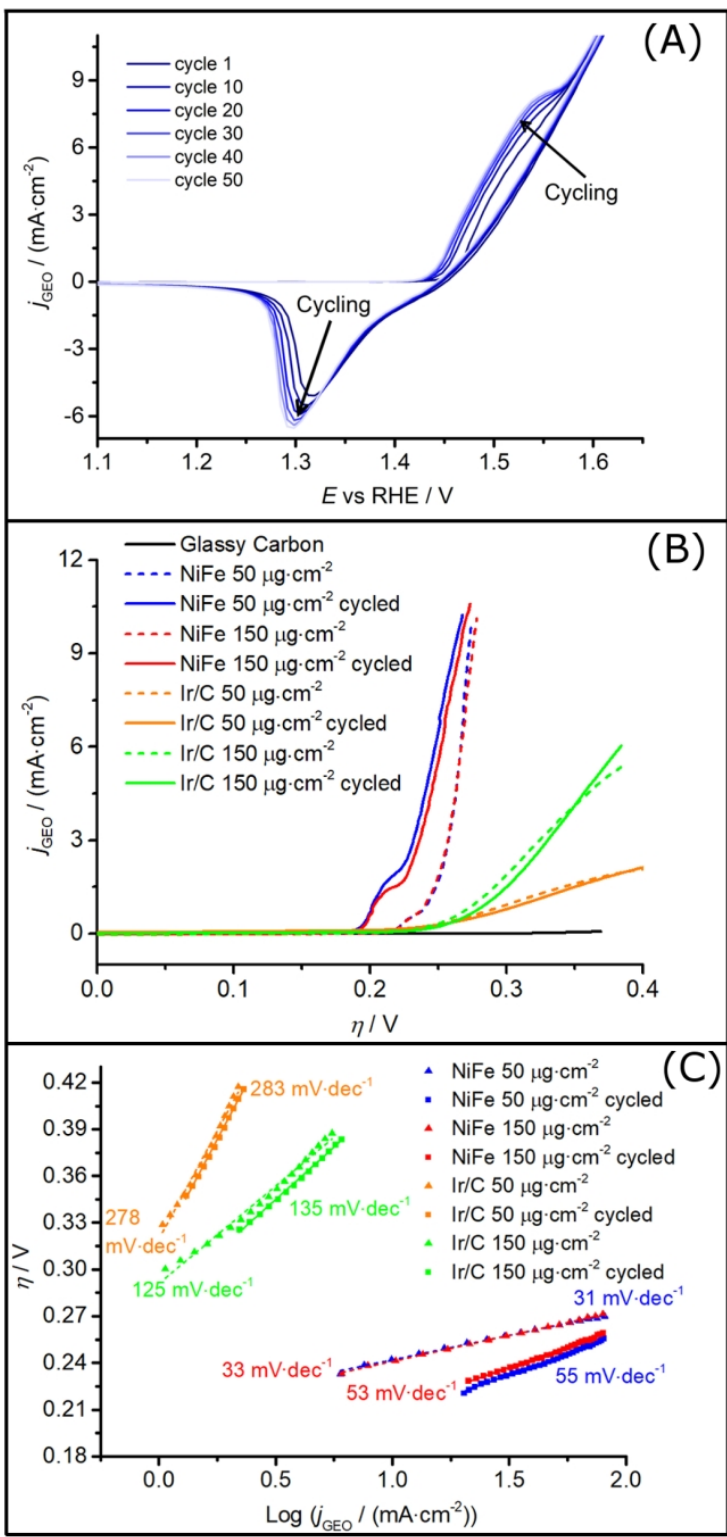

Figure 5. a) Cyclic voltammogram ( $40 \mathrm{mV} \cdot \mathrm{s}^{-1}$ ) of the $50 \mu \mathrm{g} \cdot \mathrm{cm}^{-2} \mathrm{NiFe} \mathrm{LDH}$ sample. b) Polarization curves $\left(5 \mathrm{mV} \cdot \mathrm{s}^{-1}\right)$ of the printed NiFe LDH- and Ir/C-coated electrodes with 50 and $150 \mu \mathrm{g} \cdot \mathrm{cm}^{-2}$ loadings, before and after activation/ageing. c) Tafel plot from the curves in (b). Data in (b) are iR-corrected, while data in (a) are reported without $i R$-correction. 